October 2011

\title{
Neonatal vitamin A supplementation for the prevention of mortality and morbidity in term neonates in developing countries
}

Batool A. Haider

Aga Khan University, batool.ali@aku.edu

Zulfiqar Ahmed Bhutta

Aga Khan University, zulfiqar.bhutta@aku.edu

Follow this and additional works at: https://ecommons.aku.edu/ pakistan_fhs_mc_women_childhealth_wc

Part of the Maternal and Child Health Commons

\section{Recommended Citation}

Haider, B., Bhutta, Z. A. (2011). Neonatal vitamin A supplementation for the prevention of mortality and morbidity in term neonates in developing countries. Cochrane Database of Systematic Reviews(10), 6980.

Available at: https://ecommons.aku.edu/pakistan_fhs_mc_women_childhealth_wc/52 


\section{(E) Cochrane Library}

Cochrane Database of Systematic Reviews

\section{Neonatal vitamin A supplementation for the prevention of mortality and morbidity in term neonates in developing countries (Review)}

Haider BA, Bhutta ZA

Haider BA, Bhutta ZA.

Neonatal vitamin A supplementation for the prevention of mortality and morbidity in term neonates in developing countries.

Cochrane Database of Systematic Reviews 2011, Issue 10. Art. No.: CD006980.

DOI: 10.1002/14651858.CD006980.pub2.

www.cochranelibrary.com

Neonatal vitamin A supplementation for the prevention of mortality and morbidity in term neonates in developing countries (Review) Copyright $\odot 2012$ The Cochrane Collaboration. Published by John Wiley \& Sons, Ltd. 
TABLE OF CONTENTS

HEADER . . . . . . . . . . . . . . . . . . . . . . . . . . . . . . . . . . . . . . . . . . . . .

ABSTRACT . . . . . . . . . . . . . . . . . . . . . . . . . . . . . . . . . . . . . . . . . . . . . . . . . . .

PLAIN LANGUAGE SUMMARY . . . . . . . . . . . . . . . . . . . . . . . . . . . . . . . . . . . . . . . . . . . . . .

SUMMARY OF FINDINGS FOR THE MAIN COMPARISON . . . . . . . . . . . . . . . . . . . . . . . . . . . . .

BACKGROUND . . . . . . . . . . . . . . . . . . . . . . . . . . . . . . . . . . . . . . . . . . . .

OBJECTIVES . . . . . . . . . . . . . . . . . . . . . . . . . . . . . . . . . . . . . . . . . . . . . . .

METHODS . . . . . . . . . . . . . . . . . . . . . . . . . . . . . . . . . . . . . . . .

RESULTS . . . . . . . . . . . . . . . . . . . . . . . . . . . . . . . . . . . . . . . . . . . .

Figure 1. . . . . . . . . . . . . . . . . . . . . . . . . . . . . . . . . . . . . . . 412

Figure $2 . \quad$. . . . . . . . . . . . . . . . . . . . . . . . . . . . . . . . . . . . . . . . . . . .

DISCUSSION . . . . . . . . . . . . . . . . . . . . . . . . . . . . . . . . . . . . . . 15

AUTHORS' CONCLUSIONS . . . . . . . . . . . . . . . . . . . . . . . . . . . . . . . . . . . . . . .

ACKNOWLEDGEMENTS . . . . . . . . . . . . . . . . . . . . . . . . . . . . . . . . . . . . . 17

REFERENCES . . . . . . . . . . . . . . . . . . . . . . . . . . . . . . . . . . . . . . . . . . .

CHARACTERISTICS OF STUDIES . . . . . . . . . . . . . . . . . . . . . . . . . . . . . . . . . . .

DATA AND ANALYSES . . . . . . . . . . . . . . . . . . . . . . . . . . . . . . . . . . . . . . . . . . . . . . . . . . . .

Analysis 1.1. Comparison 1 Neonatal vitamin A supplementation versus control, Outcome 1 All-cause infant mortality at 6 months: risk ratios based on cumulative risk $(\%$, adjusted for clustering). . . . . . . . . . . . . . . . . 37

Analysis 1.2. Comparison 1 Neonatal vitamin A supplementation versus control, Outcome 2 All-cause infant mortality at 6 months: rate ratios (per years of follow-up).

Analysis 1.3. Comparison 1 Neonatal vitamin A supplementation versus control, Outcome 3 All-cause infant mortality at 12 months (all infants): risk ratios based on cumulative risk (\%).

Analysis 1.4. Comparison 1 Neonatal vitamin A supplementation versus control, Outcome 4 All-cause infant mortality at 12 months: rate ratios (per years of follow-up).

Analysis 1.5. Comparison 1 Neonatal vitamin A supplementation versus control, Outcome 5 Cause-specific infant mortality at 6 months (all infants): Diarrhea.

Analysis 1.6. Comparison 1 Neonatal vitamin A supplementation versus control, Outcome 6 Cause-specific infant mortality at 6 months (all infants): Respiratory infections.

Analysis 1.7. Comparison 1 Neonatal vitamin A supplementation versus control, Outcome 7 Cause-specific infant mortality at 12 months (all infants): Diarrhoea.

Analysis 1.8. Comparison 1 Neonatal vitamin A supplementation versus control, Outcome 8 Cause-speciifc infant mortality at 12 months (all infants): Respiratory infections.

Analysis 1.9. Comparison 1 Neonatal vitamin A supplementation versus control, Outcome 9 Infant morbidity at 6 months (rate ratio): Diarrhoea. . . . . . . . . . . . . . . . . . . . . . . . . . . . . . . . .

Analysis 1.10. Comparison 1 Neonatal vitamin A supplementation versus control, Outcome 10 Infant morbidity at 6 months (rate ratio): Respiratory infections. .

Analysis 1.11. Comparison 1 Neonatal vitamin A supplementation versus control, Outcome 11 Vitamin A deficient (serum retinol $<0.70 \mathrm{micromol} / \mathrm{L}$ ) at 6 weeks of age.

Analysis 1.12. Comparison 1 Neonatal vitamin A supplementation versus control, Outcome 12 Vitamin A deficient (serum retinol $<0.70 \mathrm{micromol} / \mathrm{L}$ ) at 4 months of age.

Analysis 1.13. Comparison 1 Neonatal vitamin A supplementation versus control, Outcome 13 Anaemia (haemoglobin $<105 \mathrm{~g} / \mathrm{L})$ at $8-14$ months of age.

Analysis 1.14. Comparison 1 Neonatal vitamin A supplementation versus control, Outcome 14 Adverse events during the first 48-72 hours post supplementation.

Analysis 1.15. Comparison 1 Neonatal vitamin A supplementation versus control, Outcome 15 Adverse events during the first month post supplementation. . . . . . . . . . . . . . . . . . . . . . . . . . . . . . . 47

ADDITIONAL TABLES . . . . . . . . . . . . . . . . . . . . . . . . . . . . . . . . . . . . 47

WHAT'S NEW . . . . . . . . . . . . . . . . . . . . . . . . . . . . . . . . . . . . . . 51

HISTORY . . . . . . . . . . . . . . . . . . . . . . . . . . . . . . . . . . . . . 51

CONTRIBUTIONS OF AUTHORS . . . . . . . . . . . . . . . . . . . . . . . . . . . . . . . . . . . . . . . . . . . . .

DECLARATIONS OF INTEREST . . . . . . . . . . . . . . . . . . . . . . . . . . . . . . . . . . . . . . . 52

Neonatal vitamin A supplementation for the prevention of mortality and morbidity in term neonates in developing countries (Review)

Copyright @ 2012 The Cochrane Collaboration. Published by John Wiley \& Sons, Ltd. 
SOURCES OF SUPPORT . . . . . . . . . . . . . . . . . . . . . . . . . . . . . . . . . 52

DIFFERENCES BETWEEN PROTOCOL AND REVIEW . . . . . . . . . . . . . . . . . . . . . . . . . . $\quad 52$

INDEX TERMS . . . . . . . . . . . . . . . . . . . . . . . . . . . . . . . . . . . . . . . . $\quad 52$

Neonatal vitamin A supplementation for the prevention of mortality and morbidity in term neonates in developing countries (Review) Copyright $\odot 2012$ The Cochrane Collaboration. Published by John Wiley \& Sons, Ltd. 


\title{
[Intervention Review]
}

\section{Neonatal vitamin A supplementation for the prevention of mortality and morbidity in term neonates in developing countries}

\author{
Batool A Haider ${ }^{1}$, Zulfiqar A Bhutta ${ }^{2}$ \\ ${ }^{1}$ Departments of Epidemiology and Nutrition, Harvard School of Public Health, Boston, MA, USA. ${ }^{2}$ Division of Women and Child \\ Health, Aga Khan University Hospital, Karachi, Pakistan \\ Contact address: Zulfiqar A Bhutta, Division of Women and Child Health, Aga Khan University Hospital, Stadium Road, PO Box \\ 3500, Karachi, Sindh, 74800, Pakistan. zulfiqar.bhutta@aku.edu.
}

Editorial group: Cochrane Neonatal Group.

Publication status and date: New, published in Issue 4, 2012.

Review content assessed as up-to-date: 30 November 2010.

Citation: Haider BA, Bhutta ZA. Neonatal vitamin A supplementation for the prevention of mortality and morbidity in term neonates in developing countries. Cochrane Database of Systematic Reviews 2011, Issue 10. Art. No.: CD006980. DOI: 10.1002/14651858.CD006980.pub2.

Copyright (C) 2012 The Cochrane Collaboration. Published by John Wiley \& Sons, Ltd.

\begin{abstract}
A B S T R A C T
Background

Vitamin A deficiency is a major public health problem in developing countries. Vitamin A supplementation in children greater than six months of age has been found to be beneficial, with no effect of supplementation between one to five months. Supplementation in the neonatal period has been suggested to have an impact by increasing body stores in early infancy.
\end{abstract}

Objectives

To evaluate the role of vitamin A supplementation in term neonates in developing countries with respect to the prevention of mortality and morbidity.

\section{Search methods}

We searched the Cochrane Central Register of Controlled Trials (CENTRAL) (The Cochrane Library, May 2010), EMBASE and MEDLINE (1966 to May 2010) via PubMed.

\section{Selection criteria}

Randomised and quasi-randomised controlled trials. Trials with factorial designs were also included.

\section{Data collection and analysis}

Two review authors independently assessed trial quality and extracted the data.

\section{Main results}

Seven trials (51,446 neonates) were included in this review, with only few trials reporting disaggregated data for term infants. Therefore, we analysed data and presented estimates for term infants (where specified) followed by all infants.

Data for term neonates from three studies showed a statistically significant effect on the risk of infant mortality at six months in the vitamin A group compared with the control group (typical risk ratio (RR) 0.82; 95\% CI 0.68 to 0.99; $\mathrm{I}^{2}$ 63\%). Analysis of data for all

Neonatal vitamin A supplementation for the prevention of mortality and morbidity in term neonates in developing countries (Review)

Copyright (c) 2012 The Cochrane Collaboration. Published by John Wiley \& Sons, Ltd. 
infants from five studies showed a $14 \%$ reduction in the risk of infant mortality at six months in neonates supplemented with vitamin A compared to control; this reduction was statistically significant (typical RR 0.86; 95\% CI 0.77 to 0.97 ; $\mathrm{I}^{2} 39 \%$ ). These findings should be interpreted with caution, however, due to the small number of included studies, wide confidence intervals with upper levels close to the null effect and statistical heterogeneity. Vitamin A supplementation failed to show any significant effect on infant mortality at 12 months of age compared to control (typical rate ratio $1.03 ; 95 \%$ CI 0.87 to $1.23 ; \mathrm{I}^{2} 49 \%$ ). Limited data were available for the outcomes of cause-specific mortality and morbidity, vitamin A deficiency, anaemia and adverse events.

\section{Authors' conclusions}

Considering mortality in early infancy being a major contributory cause of overall child mortality for the under five year old group in developing countries, it is critical to obtain sound scientific evidence of the effect of vitamin A supplementation in neonates. Evidence provided in this review does indicate a potential beneficial effect of supplementing neonates with vitamin A at birth for reducing mortality in the first half of infancy. Considering the absence of a clear indication of the biological mechanism and conflicting findings from individual studies in settings with varying levels of maternal vitamin A deficiency and infant mortality, and given four additional ongoing trials with approximately 100,000 neonates being enrolled, we propose a delay in any policy recommendations for neonatal vitamin A supplementation.

\section{PLAIN LANGUAGE SUMMARY}

\section{Neonatal vitamin A supplementation for the prevention of mortality and morbidity in term neonates in developing countries}

Vitamin $\mathrm{A}$ is an important micronutrient that is required for the maintenance of normal functioning of the human body. In the developing world, many pregnant women are vitamin A-deficient. During pregnancy, additional vitamin A is required for the growth of the baby and for providing stores in the baby's liver. Deficiency of this micronutrient in the mother may also lead to its deficiency in the baby and may result in adverse effects on the baby's health. The benefits of giving vitamin A to children greater than six months of age, in reducing death and adverse effects on health, have been established but no evidence of this beneficial effect is available in infants one to five months of age. The potential benefits of vitamin A supplementation in the newborn period (during the first month of life) is under investigation and the review identified seven studies including 51,446 newborns with the intervention group supplemented with vitamin $\mathrm{A}$ in this period. There was a significant reduction in infant deaths at six months of age with the intervention when data for all infants were analysed. A similar reduction in the risk was observed for term neonates whose data were available from a subset of studies. These findings should be interpreted with caution because of the small number of studies used in these analyses and their estimates were close to the null effect of vitamin A. There are several large studies being conducted. The data from these, when available, will inform our analysis and help in establishing a definitive role of this intervention.

Neonatal vitamin A supplementation for the prevention of mortality and morbidity in term neonates in developing countries (Review) 


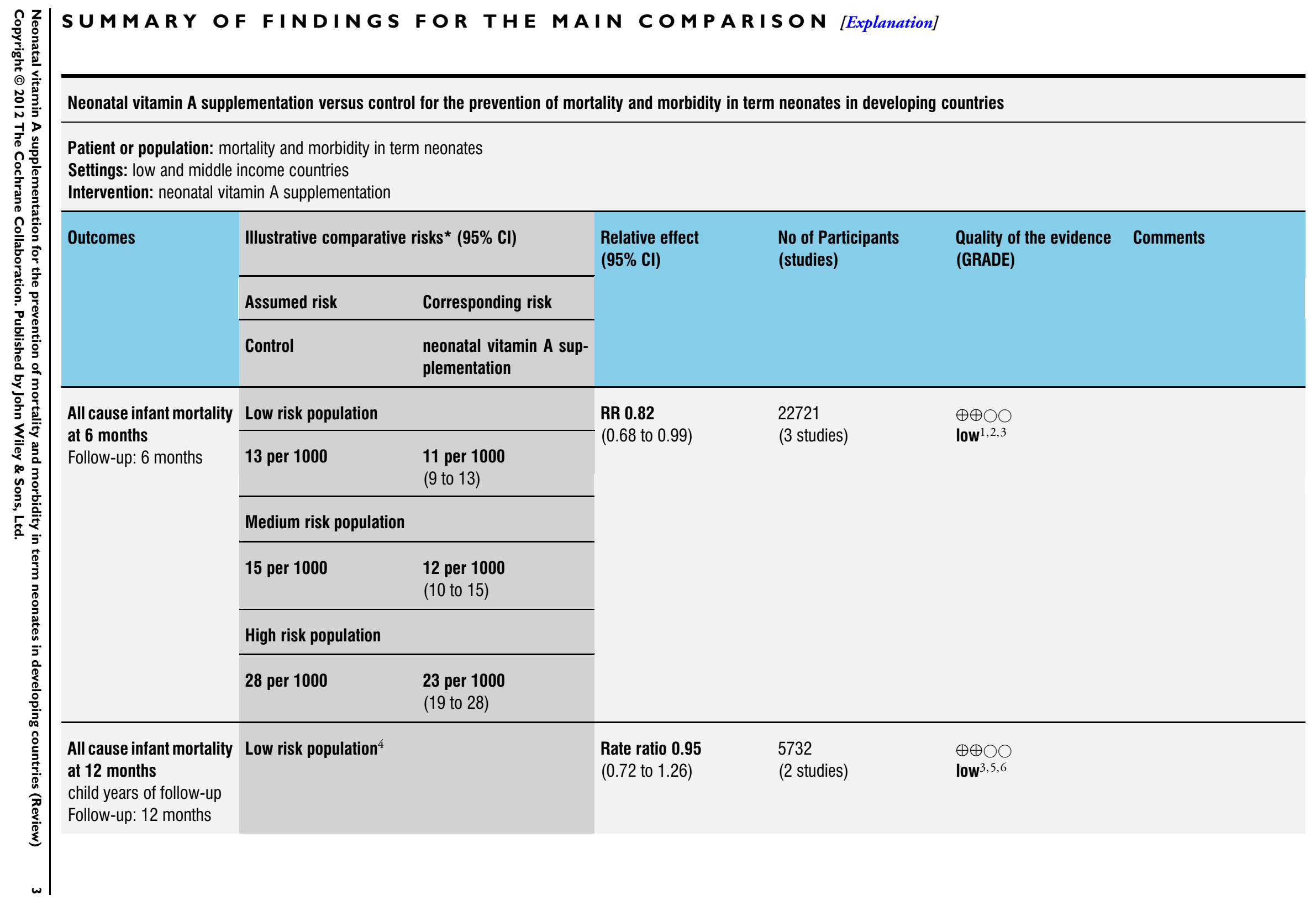




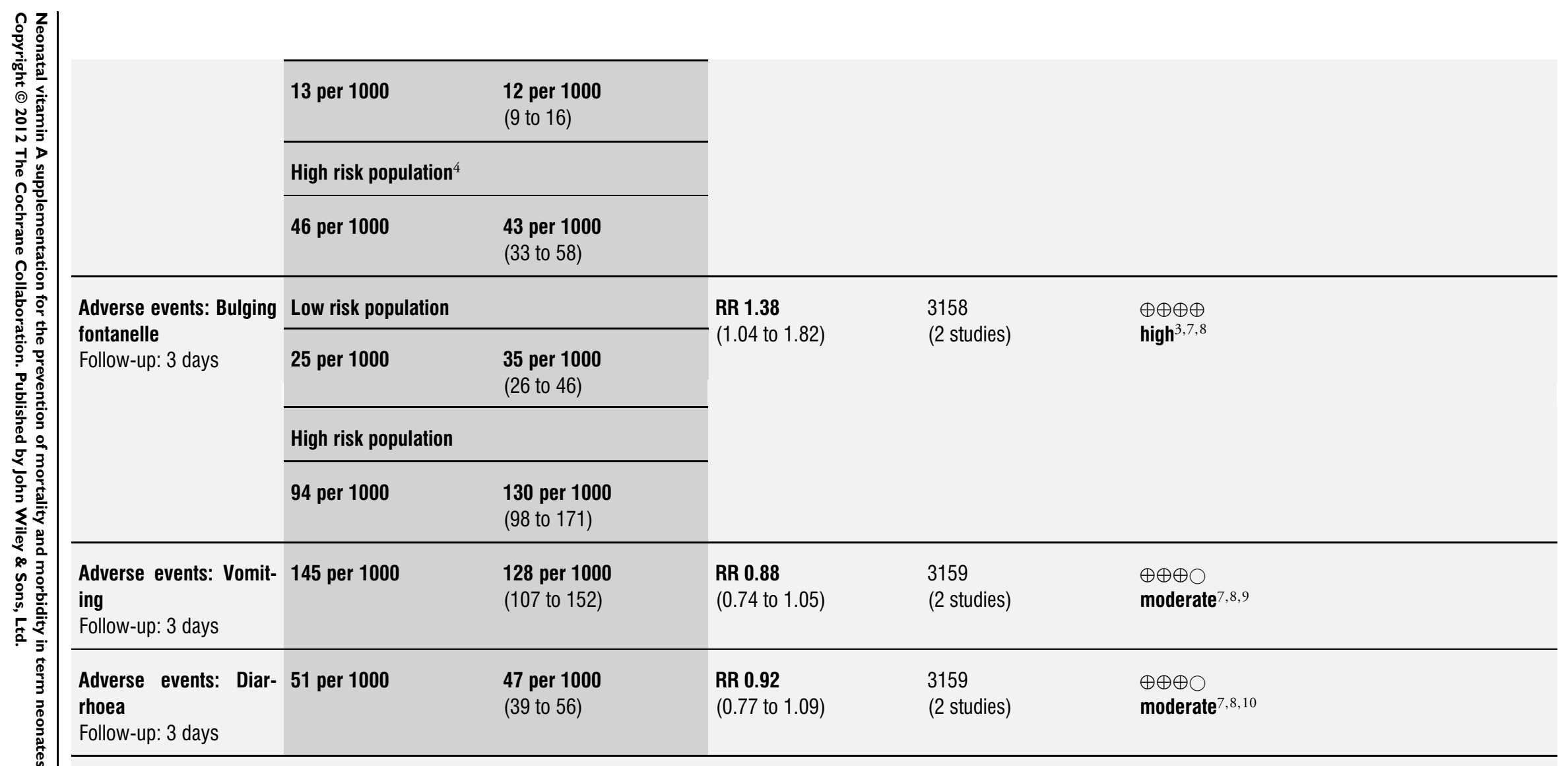

*The basis for the assumed risk (e.g. the median control group risk across studies) is provided in footnotes. The corresponding risk (and its $95 \%$ confidence interval) is based on the assumed risk in the comparison group and the relative effect of the intervention (and its $95 \% \mathrm{Cl}$ ).

Cl: Confidence interval; RR: Risk ratio;

GRADE Working Group grades of evidence

High quality: Further research is very unlikely to change our confidence in the estimate of effect.

Moderate quality: Further research is likely to have an important impact on our confidence in the estimate of effect and may change the estimate.

Low quality: Further research is very likely to have an important impact on our confidence in the estimate of effect and is likely to change the estimate.

Very low quality: We are very uncertain about the estimate. 
The risk of bias assessment identified a possible issue over the stopping procedure in Klemm 2008. A higher rate of mortality was observed in the placebo group after $2 / 3$ participants had been randomised. This study dominated the analysis (65\% weight).

${ }^{2}$ The level of statistical heterogeneity between the results of the studies was moderate (I square $63 \%$ ). The variation between the studies may have been related to differences between the study populations and settings in terms of infant mortality rates and baseline prevalence of vitamin A deficiency.

${ }^{3}$ It should be noted that there are a number of ongoing studies. The funnel plots did not indicate substantial asymmetry. The review concluded that firm policy recommendations could not be made until the studies are complete and contribute to the review.

${ }^{4}$ The rate reflects the number of events per 1000 years of child follow-up.

5 Very high levels of statistical heterogeneity (I square $82 \%$ ).

${ }^{6}$ The $95 \%$ confidence intervals include a substantial reduction in rate of mortality by $28 \%$ (translating to a reduction of 4 and 13 events/ 1000 child years in low and high risk populations), as well as a substantial increase in the mortality rate of $26 \%$ (translating to an increase of 3 and 12 events/1000 child years in low and high risk populations).

The population for these outcomes includes all infants (i.e. term and pre-term).

${ }^{8}$ Only two of the included studies reported this outcome. The authors note that data reported on this outcome specified different timepoints and could not be formally used in the meta-analysis.

9 In view of the high event rates for this outcome, the width of the confidence intervals lead to substantial variation in the absolute effect from a protective effect of vitamin $A$ to an increase in the risk of vomiting.

${ }^{10}$ There was a high level of statistical heterogeneity (I square $80 \%$ ). 


\section{B A C K G R O U N D}

\section{Description of the condition}

Vitamin A deficiency is considered to be a major public health problem in the developing countries (WHO 2000; WHO 2009). Globally, 9.8 million pregnant women are affected by night blindness, with more than 19 million having low serum retinol concentrations $(<0.70 \mu \mathrm{mol} / \mathrm{L})$. Night blindness affects $5.2 \mathrm{mil}$ lion preschool children and an estimated 190 million have low serum retinol concentrations. The prevalence of low serum retinol concentrations in pregnant women is highest in South-East Asia (17.3\%) followed by Africa (13.5\%), whereas the prevalence of night blindness is approximately the same in the two regions $(9.9 \%$ in South-East Asia versus 9.8\% in Africa) (WHO 2009).

Deficiency of vitamin A may be secondary to decreased ingestion, defective absorption and altered metabolism; or increased requirements. Factors such as low dietary fat intake or intestinal infections may also interfere with the absorption of vitamin A. Vitamin A deficiency is the most important cause of childhood blindness and contributes significantly to morbidity and mortality from common childhood infections. It is a significant contributing factor in the 2.2 million diarrhoea deaths each year among children under five years of age, and in the nearly one million measles deaths (SOWC 1998).

\section{Description of the intervention}

Vitamin A is an essential micronutrient that is required for the maintenance of normal functioning of the human body. It was the first fat soluble vitamin to be discovered and has been known to be an important dietary constituent for nearly a century (Hopkins 1912; McCollum 1915). Vitamin A is part of a family of compounds called retinoids; the naturally occurring retinoids are retinol, retinal and retinoic acid. For human physiology, retinol is the predominant form and 11-cis-retinol is the active form. The inactive retinoids, also known as provitamin A, are produced as plant pigments and are called carotenoids. Although many carotenoids occur in foods, approximately only $50 \%$ can be metabolized into the active retinoid forms. Beta-carotene, a retinol dimer, has the most significant provitamin A activity. Vitamin A is stored in the liver as retinyl esters and, when needed, is transported into blood where it is carried by retinol binding protein (RBP) for delivery to other tissues (Shenai 1993).

Vitamin A is important for the normal functioning of the visual system, immune response, gene expression, reproduction, embryogenesis and hematopoiesis (Sommer 1996). It is essential for the maintenance of normal epithelial tissues throughout the body (Wolbach 1925). Preformed vitamin A is found only in animal foods such as liver, fish and dairy products (such as milk, cheese and butter); it constitutes $65 \%$ to $75 \%$ of the dietary vitamin A intake. The remaining dietary vitamin A comes from carotenoids present in plant sources such as carrots, dark green leafy vegetables, red and orange fruits and red palm oil. The Recommended Dietary Allowances (RDAs) for vitamin A vary with age. For healthy breast-fed infants up to six months of age the average RDA is 400 $\mu \mathrm{g} / \mathrm{d}$, and for infants seven to 12 months of age the RDA is 500 $\mu \mathrm{g} / \mathrm{d}$. For children one to three years and four to eight years old, the RDA is $300 \mu \mathrm{g} / \mathrm{d}$ and $400 \mu \mathrm{g} / \mathrm{d}$, respectively (DRI 2001).

Routine consumption of large amounts of vitamin A over a period of time can result in toxic symptoms which include liver damage, headaches, vomiting, skin desquamation, bone abnormalities, joint pain and alopecia. Hypervitaminosis A appears to be due to abnormal transport and distribution of vitamin $\mathrm{A}$ and retinoids that is caused by overloading of the plasma transport mechanisms (Smith 1976). A very high single dose can also cause transient acute toxic symptoms that may include a bulging fontanelle in infants; headaches in older children and adults; and vomiting, diarrhoea, loss of appetite and irritability in all age groups. Toxicity from ingestion of food sources of preformed vitamin A is rare (Hathcock 1997).

\section{How the intervention might work}

During pregnancy, women need additional vitamin A (an additional increment of $100 \mu \mathrm{g} /$ day above basal requirements during the full gestation period) to sustain the growth of the fetus and to provide a limited reserve in the fetal liver as well as to maintain the woman's own tissue growth. Because therapeutic levels of vitamin A are generally higher than preventive levels, the safe intake level recommended during pregnancy is $800 \mu \mathrm{g}$ retinol equivalents (RE)/day. Women who are or who might become pregnant should carefully limit their total daily vitamin A intake to a maximum of $3000 \mu \mathrm{g} \mathrm{RE}(10,000 \mathrm{IU})$ to minimize the risk of fetal toxicity (WHO/NUT 1998). Infants have very low levels of vitamin A stored in the liver at birth and are dependent on breast milk as a source of vitamin A in the first few months of life. Thus, maternal vitamin A deficiency during lactation, early weaning or artificial feeding may result in vitamin A deficiency in infants (Underwood 1994). The physiologic vitamin A needs of infants born to vitamin A-adequate mothers and fed breast milk with adequate vitamin A (in excess of $30 \mu \mathrm{g} / \mathrm{dL}$ or $1.05 \mu \mathrm{mol} / \mathrm{L}$ ) are met for at least the first six months of life (Underwood 1994). Because of the need for vitamin A to support the growth rate in infancy, which can vary considerably, a requirement estimate of $180 \mu \mathrm{g}$ RE/d seems appropriate. Average consumption of human milk by such infants is about $750 \mathrm{ml} /$ day during the first six months (WHO/NUT/98.1 1998). Assuming an average concentration of vitamin A in human milk of about $1.75 \mathrm{mmol} / \mathrm{l}$, the mean daily intake would have to be about $375 \mu \mathrm{g}$ RE, which is therefore the recommended safe level. 


\section{Why it is important to do this review}

The role of vitamin A supplementation in children greater than six months of age is well established (Beaton 1993; Imdad 2010; Rice 2004). Beaton and colleagues in their meta-analysis showed that vitamin A supplementation in children six months to five years of age significantly reduced mortality by $23 \%$ (Beaton 1993). A recent Cochrane Review concluded that two oral doses of 200,000 IU of vitamin A on consecutive days in children less than two years of age with measles were associated with a reduced risk of overall mortality (RR 0.18 ; 95\% CI 0.03 to 0.61 ); similarly with pneumonia-specific mortality (RR 0.33 ; $95 \%$ CI 0.08 to 0.92 ) (Huiming 2005). The World Health Organization (WHO) recommends administration of vitamin A during vaccination contacts in order to prevent vitamin A deficiency (WHO 1998). The policy has been to supplement 100,000 IU of vitamin A at the earliest possible opportunity after six months of age. However, it has now been recommended that an additional 50,000 IU of vitamin A be administered with each of the diphtheria-tetanuspertussis (DTP) and polio vaccinations, which are usually given at six, 10 and 14 weeks of age (Sommer 2002). National and regional programmes of vitamin A supplementation are in place in over 60 countries worldwide and target children greater than six months of age. These programs are not only highly effective in reducing mortality and morbidity but, in countries in which vitamin A deficiency constitutes a public health problem, the programmes appear to be among the most cost-effective public health interventions available. Such programs address child survival in children greater than six months of age; this group accounts for a quarter of under five years of age deaths. In order to address the major proportion of deaths in children under five, children less than six months of age should be targeted. Supplementation with vitamin A between one and five months of age has not been found to have a beneficial effect (Daulaire 1992; Rahman 1995; WHO/CHD 1998). Supplementation of neonates has been suggested as a feasible approach to bolstering body stores of vitamin A in early infancy and, therefore, having an impact on mortality and morbidity (Sommer 1995; Sugana 1978).

\section{O B J E C T I VES}

To evaluate the role of vitamin A supplementation in term neonates in developing countries with respect to the prevention of mortality and morbidity.

We prespecified the following subgroups to investigate heterogeneity:

1. maternal vitamin A supplementation;

2. birth weight of neonates;

3. HIV status of the mother and infant;
4. dose and frequency of vitamin A used;

5. high baseline infant mortality;

6. co-morbidities;

7. timing of vitamin A supplementation (either within the first 48 to 72 hours or later).

\section{METHODS}

\section{Criteria for considering studies for this review}

\section{Types of studies}

All randomised controlled trials, both individual and cluster randomised and irrespective of publication status and language, evaluating the effects of vitamin A supplementation in term neonates in developing countries were included in the review. Studies using factorial design and quasi-randomised trials were also included.

\section{Types of participants}

All term neonates (born between 37 to 42 weeks of gestational age) up to 28 days after birth were included.

\section{Types of interventions}

Supplementation with vitamin A within the first 28 days of life was compared against a control (placebo or no supplementation). Any trial with continued supplementation beyond the first 28 days of life was excluded from the review. Co-interventions, if any, should have been identical in the two groups.

\section{Types of outcome measures}

\section{Primary outcomes}

1. All-cause infant mortality at six and 12 months

\section{Secondary outcomes}

1. Cause-specific infant mortality associated with acute respiratory infections and diarrhoea at six and 12 months

2. Infant morbidity at six months of age, associated with acute respiratory infections and diarrhoea, measured as at least one episode of morbidity

3. Biochemical indicator values of vitamin A deficiency (vitamin A deficiency measured as serum retinol $<0.70 \mu \mathrm{mol} / \mathrm{L}$ )

4. Blindness and signs of xerophthalmia (Bitot's spots and corneal lesions)

Neonatal vitamin A supplementation for the prevention of mortality and morbidity in term neonates in developing countries (Review)

Copyright $\odot 2012$ The Cochrane Collaboration. Published by John Wiley \& Sons, Ltd. 
5. Mean haemoglobin level or anaemia defined as haemoglobin less than the age-specific cut-off value as stated by the authors

6. Adverse events reported in trials due to vitamin A toxicity such as bulging fontanelles, vomiting and diarrhoea

\section{Search methods for identification of studies}

See: Cochrane Neonatal Review Group methods used in reviews We used the standard search strategy of the Cochrane Neonatal Review Group. The Cochrane Central Register of Controlled Trials (CENTRAL) (The Cochrane Library, 14 June 2010), EMBASE and MEDLINE (1966 to May 2010) via PubMed were searched using the following search terms: (Newborn OR infan* OR neonat*) AND (vitamin A OR retino*) Limit: publication type clinical trial.

We limited the searches to human studies. We did not apply any language restrictions. We also searched related conference proceedings for relevant abstracts. We contacted organizations and researchers in the field for information on unpublished and ongoing trials. We searched reference lists of all trials identified by the above methods. For further identification of ongoing trials the websites www.clinicaltrials.gov and www.anzctr.com were searched.

\section{Data collection and analysis}

\section{Selection of studies}

Two review authors, Batool Haider (BAH) and Zulfiqar Bhutta (ZAB), independently assessed all the potential studies we identified as a result of the search strategy for inclusion. We resolved any disagreement through discussion.

\section{Data extraction and management}

We designed a form to extract data. For eligible studies, two review authors (BAH and ZAB) extracted the data using the agreed form. We resolved discrepancies through discussion. Data were entered into the Review Manager software (RevMan 2008) and checked for accuracy.

\section{Assessment of risk of bias in included studies}

Two review authors (BAH and ZAB) independently assessed the risk of bias for each study using the criteria outlined in the Cochrane Handbook for Systematic Reviews of Interventions (Higgins 2008). We resolved any disagreement by discussion.

\section{(I) Sequence generation (checking for possible selection} bias)

We described for each included study the method used to generate the allocation sequence, if it was in sufficient detail to allow an assessment of whether it should produce comparable groups.

We assessed the method as:

- low risk (adequate) (any truly random process, e.g. random number table; computer random number generator);

- high risk (inadequate) (any non-random process, e.g. odd or even date of birth; hospital or clinic record number);

- unclear risk.

(2) Allocation concealment (checking for possible selection bias)

We described for each included study the method used to conceal the allocation sequence if in sufficient detail to determine whether intervention allocation could have been foreseen in advance of or during recruitment, or changed after assignment.

We assessed the methods as:

- low risk (adequate) (e.g. telephone or central randomisation; consecutively numbered sealed opaque envelopes);

- high risk (inadequate) (open random allocation; unsealed or non-opaque envelopes, alternation; date of birth);

- unclear risk.

\section{(3) Blinding (checking for possible performance bias)}

We described for each included study the methods used, if any, to blind study participants and personnel from knowledge of which intervention a participant received. Studies were judged at low risk of bias if they were blinded or if we judged that the lack of blinding could not have affected the results.

We assessed the methods as:

- low risk (adequate), high risk (inadequate) or unclear risk for participants;

- low risk (adequate), high risk (inadequate) or unclear risk for personnel;

- low risk (adequate), high risk (inadequate) or unclear risk for outcome assessors.

(4) Incomplete outcome data (checking for possible attrition bias through withdrawals, dropouts, protocol deviations)

We described for each included study, and for each outcome or class of outcomes, the completeness of data including attrition and exclusions from the analysis. We stated whether attrition and exclusions were reported, the numbers included in the analysis at each stage (compared with the total number of randomised participants), reasons for attrition or exclusion where reported, and whether missing data were balanced across groups or were related to outcomes. We assessed methods as: 
- low risk (adequate);

- high risk (inadequate);

- unclear risk.

\section{(5) Selective reporting bias}

We described for each included study how we investigated the possibility of selective outcome reporting bias and what we found. We assessed the methods as:

- low risk (adequate) (where it was clear that all of the study's prespecified outcomes and all expected outcomes of interest to the review have been reported);

- high risk (inadequate) (where not all the study's prespecified outcomes have been reported; one or more reported primary outcomes were not prespecified; outcomes of interest were reported incompletely and so cannot be used; the study failed to include results of a key outcome that would have been expected to have been reported);

- unclear risk.

\section{(6) Other sources of bias}

We described for each included study any important concerns we have about other possible sources of bias. We assessed whether each study was free of other problems that could put it at risk of bias as:

- yes;

- no;

- unclear.

\section{(7) Overall risk of bias}

We made explicit judgements about whether studies were at high risk of bias, according to the criteria given in the Cochrane Handbook for Systematic Reviews of Interventions (Higgins 2008). We explored the impact of the overall risk of bias by undertaking sensitivity analysis for primary outcomes. We considered a study to be of high quality if it was judged to have adequate sequence generation and allocation concealment, with either adequate blinding or methods for dealing with incomplete outcome data.

\section{Measures of treatment effect}

\section{Dichotomous data}

For dichotomous data, we presented results as summary risk ratios or rate ratios with $95 \%$ confidence intervals $(\mathrm{CI})$.

\section{Continuous data}

There were no continuous outcomes in this review.

\section{Unit of analysis issues}

There were two cluster randomised trials (Klemm 2008; West 1995 ) included in this review. Klemm et al reported that the observed design effect was $0.9 \%$. In West 1995 , the $95 \%$ confidence intervals (CIs) of the effect estimates were inflated by $10 \%$ to account for the impact of design on the study findings. We estimated that the $10 \%$ increase in the $95 \%$ CIs gave an intracluster correlation coefficient (ICC) of 0.04 for the cohort of infants administered vitamin $\mathrm{A}$.

\section{Data synthesis}

We analysed the data using a generic inverse variance approach to meta-analysis, using Review Manager software (RevMan 2008), and generated risk ratio or rate ratio estimates with $95 \%$ CIs for the dichotomous outcomes. For this approach, the data were entered as natural logarithms (as log risk ratios and SE of log risk ratio or $\log$ rate ratios and SE of log rate ratio) for each individual study, with data either extracted from the published papers or obtained from the authors if not presented in the papers. Data used for the infant mortality analyses along with their source are presented in 'Additional tables'. We used the fixed-effect method for combining data where trials were examining the same intervention and the trial populations and methods were judged to be sufficiently similar.

The review objective was to evaluate the effect of vitamin A supplementation in term neonates. The studies included in this review had enrolled all births that were identified in their study settings without using a restriction for gestational age, of either < 37 or $\geq 37$ weeks, which would have allowed us to use the term data only. Birthweight was used as a criterion in two studies: Benn 2008 enrolled normal birthweight neonates (birthweight $\geq 2500$ g) and Benn 2010 recruited low birthweight neonates (birthweight $<2500$ g) only. Data for term neonates was presented separately only in the published paper of one study, for the infant mortality outcome at six months (Klemm 2008), whereas mortality data for term neonates only for other studies was obtained by contacting the study authors. Information about the gestational age was not available in West 1995 (Keith West; personnel communication 2008). Considering the small number of studies included in the review and the availability of data for primary outcomes, we analysed data for term neonates, where available, followed by the analysis for all infants. For all secondary outcomes, data in published papers were presented for all infants together and have been analysed as such. As the inclusion criterion of Benn 2008 was birthweight at least $2500 \mathrm{~g}$, we assumed that a greater proportion of neonates would be term babies and have analysed its data as such in our term neonate analysis. We used the term 'all infants' to refer to aggregated term and preterm infants data throughout this review.

There were two studies which had maternal supplementation with vitamin A, either in the postpartum period (Malaba 2005) or dur-

Neonatal vitamin A supplementation for the prevention of mortality and morbidity in term neonates in developing countries (Review) 
ing pregnancy (Klemm 2008). Malaba et al randomised motherinfant pairs to the four treatment arms (described in detail in the table 'Characteristics of included studies') whereas Klemm et al randomised neonates within each of three previously randomised treatment arms of a maternal supplementation trial of vitamin A. This resulted in two neonatal treatment arms in Klemm 2008 which were balanced across the maternal supplementation arms. Both studies reported no significant interaction between maternal and neonatal supplementation with vitamin A and we have used data for all neonates included in these studies on the basis of their randomisation to the neonatal vitamin A intervention or control group.

\section{Subgroup analysis and investigation of heterogeneity}

We measured heterogeneity among the trials by calculating the $\mathrm{I}^{2}$ statistic. Values of the $\mathrm{I}^{2}$ statistic greater than $50 \%$ were considered to represent substantial heterogeneity, in which case we planned to explore heterogeneity by undertaking prespecified subgroup analysis. However, the small number of studies included in the review precluded any evaluation of heterogeneity, when identified. We planned to investigate publication bias for outcomes with more than 10 included studies. However, we did not investigate the presence of this bias as the number of studies included was small.

\section{RES U L T S}

\section{Description of studies}

\section{Included studies}

Seven studies including 51,446 neonates were included in this review.

The study by Humphrey et al was conducted in a single tertiary care hospital in Indonesia (Humphrey 1996) as a safety trial for vitamin A supplementation at the time of birth. This was a randomised double blind placebo controlled trial of 2067 infants with birthweight $>1500 \mathrm{~g}$ and without any critical illness. The infants were randomly assigned to receive a single oral dose of vitamin A $(50,000 \mathrm{IU})$ or placebo within 24 hours of delivery. The two groups were similar at baseline for maternal, infant and household characteristics.

The study conducted by West et al (West 1995) in Nepal was part of a large cluster randomised, double blind, placebo controlled trial of vitamin A supplementation in preschool children. A total of 11,918 infants less than six months of age, of which 1621 were neonates, were enrolled and administered vitamin A (50,000 IU in $<$ one month old infants and 100,000 in one to five month old infants) or placebo. Baseline characteristics of the two groups were similar.

The study conducted in India by Rahmatullah et al (Rahmathullah 2003) was also a randomised, double blind, placebo controlled trial in which all live born infants resulting from pregnancies within the participating villages were eligible for inclusion. A total of 11,619 newborn infants born to consenting mothers who were residing in the study area were enrolled. Infants were given two doses of vitamin A or placebo with the first dose being administered within the first 48 hours of delivery and the second dose within 24 hours of the first dose. Baseline characteristics of the families, mothers and infants were similar between the treatment groups.

The Zimbabwe study (Malaba 2005) was a randomised, double bind, placebo controlled trial using a two by two factorial design. Mother-infant pairs were eligible for inclusion if the mother planned to reside in the study area after delivery. None of the two had any life threatening illness and the infant's birthweight was > $1500 \mathrm{~g}$. Around 14,110 infant-mother pairs were enrolled within 96 hours of delivery and were assigned to either of the following groups: Aa (vitamin A supplementation to both the mother and infant), Ap (vitamin A to the mother and placebo to infant), pa (placebo to mother and vitamin A to infant) and pp (placebo to both the mother and infant). The vitamin A dose for mothers was $400,000 \mathrm{IU}$ and for infants it was 50,000 IU. All the treatment groups were similar at baseline for maternal, household and other related variables.

The study conducted by Klemm et al in Bangladesh (Klemm 2008) was a cluster randomised, double bind, placebo controlled trial which was nested within an ongoing parent trial of vitamin A supplementation in pregnant women. All infants born to consenting mothers of the original trial were included in the current trial. A total of 15,948 infants were administered vitamin A (50,000 IU) or placebo at home as soon as possible after birth. Baseline characteristics of the mothers and infants in this study were comparable at baseline.

Two studies were conducted in Guinea Bissau by Benn et al. Benn 2008 was a randomised, double blind, placebo controlled trial which included 4345 normal birthweight infants (birthweight at least $2500 \mathrm{~g}$ ). For births occurring at the national hospital or local health centres, mothers were invited to participate in the study at the time of Bacille Calmette-Guérin (BCG) vaccination. For home births, mothers were invited to participate at the time of their visit to the local health centres for BCG vaccination. All infants with birthweight at least $2500 \mathrm{~g}$, without any serious medical condition or malformation, for whom parental consent was available were randomised to either oral drops of vitamin A (50,000 IU) or placebo. The treatment groups were similar at baseline for various baseline characteristics. The other study by these investigators was conducted in parallel with Benn 2008. Benn 2010 was a two by two factorial, randomised, double blind, placebo controlled trial in low birth weight neonates (birthweight $<2500 \mathrm{~g}$ ). This study included 1736 neonates randomised to either 25,000 IU vitamin 
A or placebo, as well as to early BCG vaccine or the usual late BCG vaccine.

See the table 'Characteristics of included studies' for further details.

\section{Ongoing studies}

There are four ongoing studies that are being conducted in Pakistan, India, Ghana and Tanzania. All four studies are randomised, double blind, placebo controlled trials, with the one in Pakistan using a cluster randomised design.

The inclusion criteria for Pakistan 2008 were live born infants without congenital malformations or serious birth injury from all pregnancies within participating villages, with a sample size of 7,400 infants. The study was designed as an effectiveness trial with vitamin A delivery through the Lady Health Workers program of the government of Pakistan. Intervention included routine postpartum care and vitamin A supplementation (50,000 IU) to the newborn within 48 to 72 hours of birth whereas the control group received routine postpartum care only. Outcomes to be evaluated were all-cause and cause-specific infant mortality at six months, incidence of serious infections (sepsis, pneumonia and diarrhoea), measurement of serum retinol values and rates of breastfeeding in the two groups. Recruitment and follow up for this study have been completed and data analysis is in progress.

The studies being planned in India, Ghana and Tanzania also aim to evaluate the effect of supplementation of 50,000 IU of vitamin A against control. The Indian study is being conducted in two districts in the state of Haryana with an estimated sample size of 40,200 neonates (India 2010). All births in the study area contacted by the enrolment team within the eligible age window and with the parent's consent to participate will be included. The eligible age window has been defined as up to 60 hours after birth. Outcomes that will be evaluated include infant mortality at six months, mortality in the neonatal period (during the first month of life); incidence of severe morbidity, defined as hospitalizations due to any illness in the first six months of infancy; potential adverse effects of vitamin A; and vitamin A status in a subgroup of newborns at two weeks and three months of age and their caregivers.

The methodologies of the studies in Ghana and Tanzania were found to be similar. The Ghana study will be conducted in seven contiguous districts in the Brong Ahafo region of central rural Ghana (Ghana 2010) with a target sample size of 28,000 neonates. The Tanzanian study will be conducted in Dar-es-Salaam and the Kilombero and Ulanga districts in Ifakara (Tanzania 2010). The estimated sample size for this study is 32,000 neonates. Inclusion criteria in both studies are all births in the study area that are contacted by the study team on the day of birth or in the next two days. Both singleton and multiple births are eligible for inclusion and each infant will be provided a unique identification number. Intervention includes vitamin A 50,000 IU once orally within the first three days of life, keeping a minimum period of two hours between birth and dosing. Similar outcomes will be evaluated in the two studies, which are all-cause infant mortality assessed at six months of age, all-cause neonatal mortality assessed at one month of age, incidence of severe morbidity defined as hospitalisations due to any illness in the first six months of infancy, potential adverse effects of vitamin $\mathrm{A}$, and vitamin $\mathrm{A}$ and $\mathrm{C}$ reactive protein (CRP) status in a subsample of infants at two weeks and three months of age.

See the table 'Characteristics of ongoing studies' for further details.

\section{Excluded studies}

Two studies were excluded from the review (Bezzera 2009; Bhaskaram 1998). Bezzera 2009 included vitamin A supplementation of mothers only in the immediate postpartum period; their neonates were not supplemented. Bhaskaram 1998 supplemented mothers only with vitamin A within 24 hours of delivery while all neonates were given oral poliovirus vaccine (OPV) between 48 and 72 hours after birth.

\section{Risk of bias in included studies}

Three studies adequately randomised neonates to the treatment groups (Benn 2008; Benn 2010; Malaba 2005) with a clear description of the method used for generating the randomisation sequence. Four studies did not provide sufficient details to allow judgement of the adequacy of their methods (Humphrey 1996; Klemm 2008; Rahmathullah 2003; West 1995). The method of allocation concealment was clearly described in four studies (Benn 2008; Benn 2010; Humphrey 1996; Malaba 2005) whereas it was not described in sufficient detail in Klemm 2008, Rahmathullah 2003 and West 1995. Blinding of participants, study personnel and outcome assessors was clearly described and achieved in all included studies. The post randomisation attrition and exclusion of participants was: 1.6\% (Benn 2008), 18.7\% (Benn 2010), 11\% (Humphrey 1996), 7\% (Klemm 2008), 41.8\% (Malaba 2005) and $18.9 \%$ (Rahmathullah 2003), with reasons for attrition and exclusion of the participants described in the papers. Exclusion and attrition were $1.04 \%$ in West 1995 and details of these were not provided. Evaluation of selective outcome reporting by reviewing either trial registration documents, if available, or methodology in published papers showed that all trials have reported their findings for prespecified or expected outcomes except for Humphrey 1996 where it was unclear. We identified three trials with potential high risk of other bias: Benn 2008 and Benn 2010 conducted post hoc analyses after assuming that vitamin A might be more beneficial to boys whereas Klemm 2008 was terminated after randomisation of two-thirds of the planned number of infants due to the significantly higher mortality in the control group. Malaba 2005 was found to be free of other bias and the risk of other bias was uncertain in the remaining three trials due to insufficient information (Humphrey 1996; Rahmathullah 2003; West 1995). 
See the table 'Characteristics of included studies' for further details on risk of bias in included studies. A graphical presentation of our individual judgments per item per study is provided in Figure 1 and a summary graph is given in Figure 2.

Figure I. Methodological quality summary: review authors' judgements about each methodological quality item for each included study.

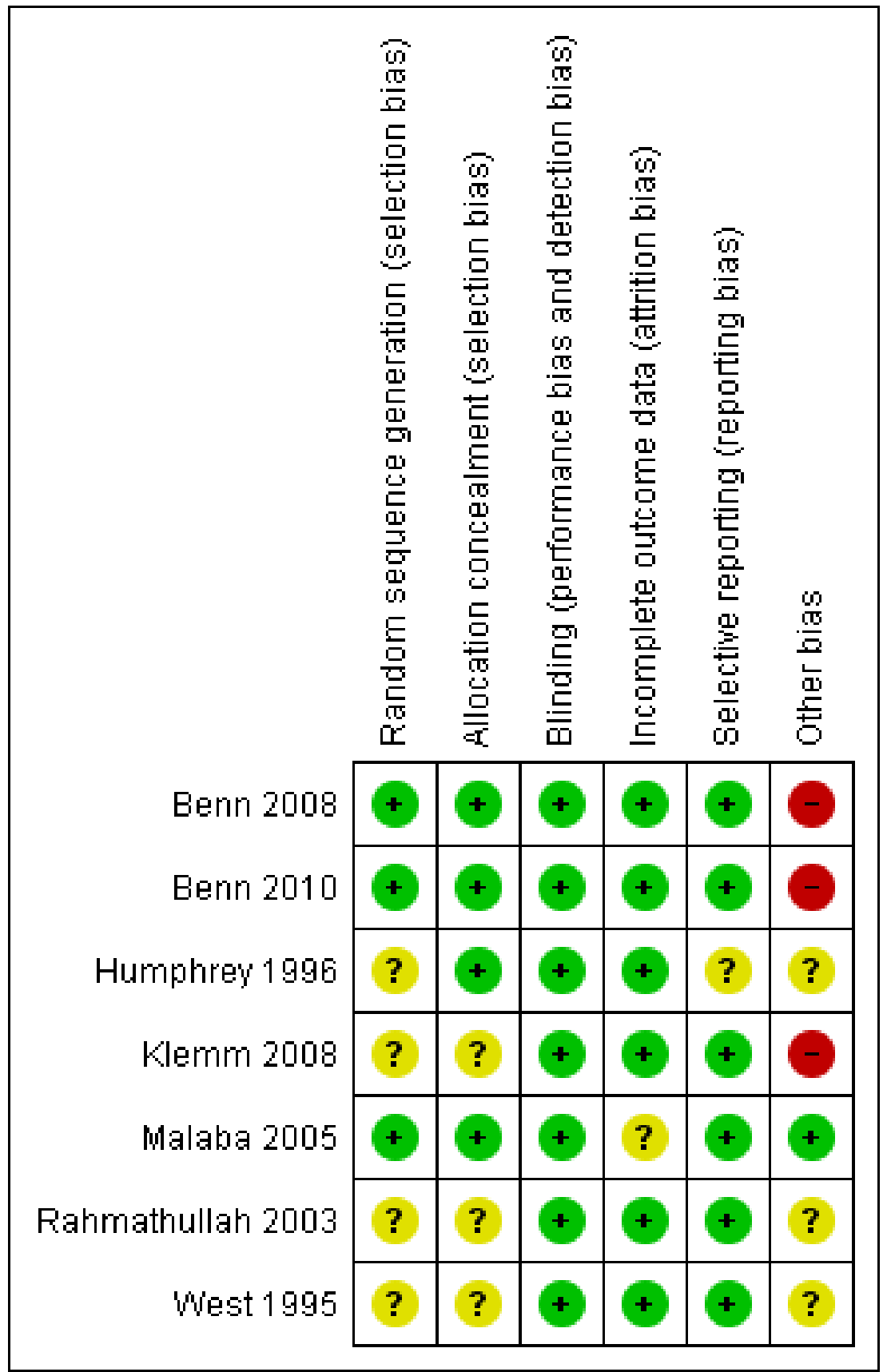

Neonatal vitamin A supplementation for the prevention of mortality and morbidity in term neonates in developing countries (Review) 
Figure 2. Methodological quality graph: review authors' judgements about each methodological quality item presented as percentages across all included studies.

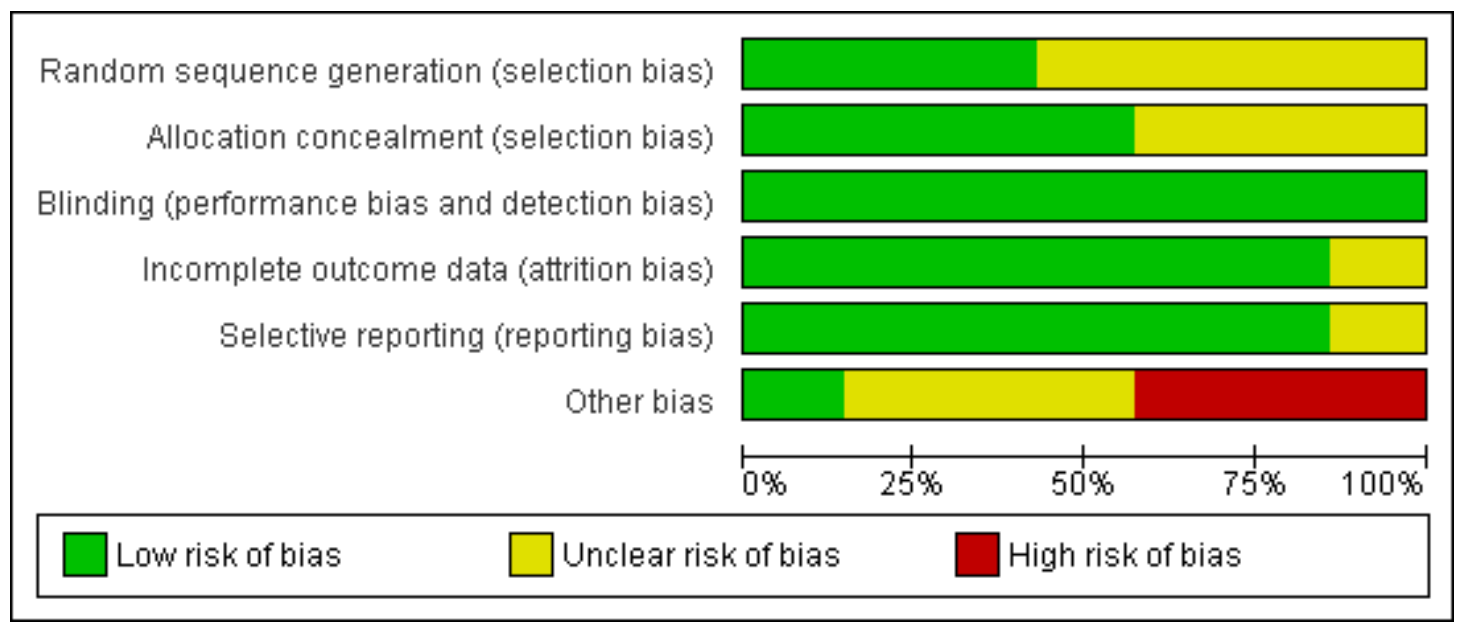

\section{Effects of interventions}

See: Summary of findings for the main comparison Neonatal vitamin A supplementation versus control for the prevention of mortality and morbidity in term neonates in developing countries A summary of findings table based on the outcomes in term neonates has been included in this review, which is in accordance with the methodology recommended by GRADE (Summary of findings for the main comparison).

\section{Neonatal vitamin A supplementation versus placebo}

\section{Primary outcomes}

\section{All-cause infant mortality at six months of age}

An overview of the type and source of data for this outcome is presented in Table 1.

Six included studies (Benn 2008; Benn 2010; Humphrey 1996; Klemm 2008; Malaba 2005; Rahmathullah 2003) measured infant mortality at six months of age. West 1995 measured mortality at four months of age and this data has been included in the six month mortality analysis.
All-cause infant mortality at six months of age: risk ratios based on cumulative risk (\%) (Outcome 1.1)

Data from five studies were measured as risk ratios based on cumulative risk.

The pooled estimate of data for term infants from three studies (Humphrey 1996; Klemm 2008; Malaba 2005) suggests that the risk of death from any cause at six months of age for neonates who were supplemented with vitamin A is $18 \%$ lower than control, which is statistically significant (typical RR $0.82 ; 95 \%$ CI 0.68 to $0.99)$ (Analysis 1.1.1). The level of statistical heterogeneity in this analysis was $63 \%$. As the number of studies included was small, a subgroup analysis to investigate heterogeneity was not considered reliable. Given substantial statistical heterogeneity and the small number of included studies, these findings should be interpreted with caution.

The pooled estimate of the data for all infants from five studies (Humphrey 1996; Klemm 2008; Malaba 2005; Rahmathullah 2003; West 1995) showed a statistically significant reduction of $14 \%$ in the risk of death from any cause for neonates supplemented with vitamin A as compared to control (typical RR 0.86; 95\% CI 0.77 to 0.97 ). The level of statistical heterogeneity for this analysis was less than 50\% ( $\mathrm{I}^{2} 39 \%$ ) (Analysis 1.1.2).

There was only one high quality study included in these analyses (Malaba 2005), hence a sensitivity analysis on the basis of study quality was not undertaken. 
All-cause infant mortality at six months of age: rate ratios (per years of follow up) (Outcome 1.2)

Data from four studies were analysed as rate ratios (per year of follow up).

Pooled estimates for term neonates from Benn 2008 and Rahmathullah 2003 showed no evidence of a significant effect on the rate of death from any cause at six months of age in those that received vitamin $\mathrm{A}$ as compared to control (typical rate ratio 0.91; $95 \%$ CI 0.73 to 1.13 ) (Analysis 1.2.1). Analysis for all infants data from four studies (Benn 2008; Benn 2010; Rahmathullah 2003; West 1995) also did not reach statistical significance (typical rate ratio $0.91 ; 95 \%$ CI 0.77 to 1.06 ) (Analysis 1.2.2). The levels of statistical heterogeneity were: $\mathrm{I}^{2}$ statistic $51 \%$ and $28 \%$ for term and all infants analyses, respectively.

Analysis of two high quality studies showed similar effects of vitamin A on the rate of death at six months as compared to control (typical rate ratio $0.89 ; 95 \%$ CI 0.75 to 1.05 ) (Rahmathullah 2003; Benn 2008; Benn 2010) (data not shown).

\section{All-cause infant mortality at 12 months of age (Outcomes 1.3 and 1.4)}

An overview of the type and source of data for this outcome is presented in Table 2.

Four included studies (Benn 2008; Benn 2010; Humphrey 1996; Malaba 2005) measured infant mortality at 12 months of age.

Analysis of term neonate data from two studies as rate ratios ( Benn 2008; Humphrey 1996) showed no evidence of a significant effect on infant mortality from any cause at 12 months of age in neonates supplemented with vitamin A as compared to control, with statistical heterogeneity of $82 \%$ (typical rate ratio $0.95 ; 95 \%$ CI 0.72 to 1.26 ) (Analysis 1.4). Further subgroup analysis was not undertaken due to the small number of studies included. The pooled estimate for all infants data from four studies also showed no evidence of a significant effect of supplementation of neonates with vitamin A on infant mortality at 12 months of age compared to controls (typical risk ratio $1.02 ; 95 \%$ CI 0.87 to 1.20 ; typical rate ratio 1.03 ; $95 \%$ CI 0.87 to 1.23 ) (Analysis 1.4 and 1.4 .2 ). The level of statistical heterogeneity was lower than $50 \%$ (I2 49\% for both risk and rate ratios). Three high quality studies (Benn 2008; Benn 2010; Malaba 2005) showed similar effects on infant mortality at 12 months of age (typical risk ratio 1.07; 95\% CI 0.91 to 1.27 ) (data not shown).

\section{Secondary outcomes}

\section{Cause-specific infant mortality at six months of age: diarrhoea and acute respiratory infections (Outcomes 1.5 and 1.6)}

Infant mortality related to diarrhoea and acute respiratory infections at six months of age was measured by two studies (Humphrey
1996; Rahmathullah 2003). Data for all infants for Humphrey 1996 were measured as risk ratios based on cumulative risk, which showed no significant effect of vitamin A supplementation on diarrhoea and respiratory infections as compared to control (diarrhoea-specific infant mortality: risk ratio $0.20 ; 95 \%$ CI 0.02 to 1.68 ; and acute respiratory infection-specific infant mortality: risk ratio 0.66 ; $95 \%$ CI 0.11 to 3.91 ). Data for all infants from Rahmathullah 2003 were presented as rate ratios (per years of follow up) and showed a similar non-significant effect of vitamin A on the rate of diarrhoea-specific and acute respiratory infectionspecific infant mortality at six months of age as compared to control (diarrhoea-specific infant mortality: rate ratio 0.67 ; $95 \% \mathrm{CI}$ 0.32 to 1.39 ; and acute respiratory infection-specific infant mortality: rate ratio $1.00 ; 95 \%$ CI 0.56 to 1.79 ).

\section{Cause-specific infant mortality at 12 months of age: diarrhoea and acute respiratory infections (Outcomes 1.7 and 1.8)}

Infant mortality related to diarrhoea and acute respiratory infections at 12 months of age was measured by three studies (Benn 2008; Humphrey 1996; Malaba 2005).

Data for all infants for Humphrey 1996 were measured as risk ratios based on cumulative risk and showed no evidence of a significant effect of vitamin A on death due to diarrhoea and acute respiratory infections as compared to control (diarrhoea-specific infant mortality: risk ratio $0.40 ; 95 \%$ CI 0.08 to 2.03 and acute respiratory infection-specific infant mortality: risk ratio $0.66 ; 95 \%$ CI 0.11 to 3.95). Benn 2008 and Malaba 2005 analysed data for all infants as rate ratios. Pooled data suggested no evidence of a significant effect of vitamin A on diarrhoea-specific and acute respiratory infections-specific infant mortality at 12 months of age as compared to control (typical rate ratios: $1.32 ; 0.80$ to 2.16 ; $\mathrm{I}^{2}$ $0 \%$; and $1.10 ; 0.48$ to $2.50 ; \mathrm{I}^{2} 0 \%$, respectively).

Cause-specific infant morbidity at 6 months of age: diarrhoea and acute respiratory infection (Outcomes 1.9 and 1.10)

Two trials (Malaba 2005; Rahmathullah 2003) measured infant morbidity at six months of age as rate ratios (per year of follow up). Pooled estimates showed no significant effect of vitamin A as compared to control on the rate of diarrhoea and acute respiratory infections in infants at six months of age (typical rate ratio: 1.05; 0.99 to $1.10 ; \mathrm{I}^{2} 0 \%$; and $1.01 ; 95 \%$ CI 0.96 to 1.05 ; $\mathrm{I}^{2} 85 \%$, respectively). A subgroup analysis to investigate heterogeneity was not considered due to the small number of studies contributing data to this analysis.

\section{Vitamin A deficiency (Outcomes 1.11 and 1.12)}

Vitamin A deficiency defined as serum retinol value $<0.70 \mu \mathrm{mol} /$ L was available for all infants from one study only (Benn 2008), which showed no evidence of a significant effect of vitamin A 
supplementation on vitamin A deficiency as compared to control (at 6 weeks: risk ratio $0.94 ; 0.75$ to 1.19 ; and at four months: risk ratio: $1.02 ; 0.64$ to 1.62 ).

\section{Anemia (Outcome 1.13)}

The impact on anaemia was measured in only one study (Malaba 2005), for all infants born to both HIV positive and negative women. Vitamin A supplementation in neonates did not lead to a significant impact on anaemia (haemoglobin $(\mathrm{Hb})<105 \mathrm{~g} / \mathrm{L}$ ) at 8 to 14 months of age (risk ratio $0.97 ; 95 \%$ CI 0.87 to 1.07 ) compared to control.

\section{Adverse events (Outcomes 1.14 and 1.15)}

Data for adverse events in all infants during the first 48 to 72 hours could be pooled only from two studies (Benn 2008; Humphrey 1996), and only one study (Benn 2008) presented adverse events at one month of age. Pooled estimates suggested no evidence of a significant increase in adverse events during the first 48 to 72 hours, specifically bulging fontanelle (typical risk ratio 1.38; $95 \%$ CI 1.04 to 1.82 ), diarrhoea (typical risk ratio 0.92 ; $95 \%$ CI 0.77 to 1.09 ) and vomiting (typical risk ratio 0.88 ; $95 \%$ CI 0.74 to 1.05 ), in the vitamin A group versus the control group. Benn 2008 showed no evidence of a significant increase in adverse events during the first month post supplementation (risk ratio diarrhoea 1.07 ; 0.46 to 2.51 ; and vomiting $1.22 ; 0.57$ to 2.58 ).

\section{Other outcomes}

The included studies did not measure the impact of neonatal vitamin A supplementation on blindness and xerophthalmia.

\section{ISCUSSIO N}

The objective of this review was to evaluate the effect of supplementing term neonates with vitamin A as compared to unsupplemented controls. As the term neonatal outcome data were only available for a small number of studies, and then for infant mortality outcomes only, we analysed and presented estimates for both term neonates (where specified) and all infants for the various prespecified outcomes. Our analysis for all infants provided evidence of a $14 \%(95 \%$ CI $3 \%$ to $23 \%)$ reduction in the risk of death at six months of age in the vitamin A supplemented group as compared to the controls. This was statistically significant. Analysis of the term neonatal outcome included data from a subset of studies included in the all infant analysis and also showed a significant reduction in the risk of death in the first six months of life (reduction of $18 \%$; $95 \%$ CI $1 \%$ to $32 \%$ ). These findings should be interpreted with caution due to the small number of studies contributing data to these analyses, statistical heterogeneity and wide confidence intervals that are close to the null effect. Three studies (Benn 2008; Benn 2010; Rahmathullah 2003) had analysed data as rates (per year of follow up) which precluded their inclusion in this analysis. They have been analysed separately, whereas the study by West et al did not include information on gestational age. Further assessment of the effect in term neonates is needed, with data for all studies included in the review.

Analysis of the effect on infant mortality at 12 months of age of vitamin A supplementation in neonates provided no evidence of a significant effect on this outcome. Of four included studies, only one by Humphrey et al in Indonesia (Humphrey 1996) showed a highly significant effect on mortality at the end of the first year of life. Overall, the review findings suggest a potential effect of this intervention in the first half of infancy only.

Deficiency of vitamin A is a major nutritional concern in many countries of the world. All studies included in this review were conducted in developing countries with varying levels of vitamin A deficiency and infant mortality. The first trial of vitamin A in neonates was conducted as a safety trial in Indonesia (Humphrey 1996). This trial had shown significant reduction in the risk of mortality, with a difference in survival between the groups notable after the first month of life and becoming consistent after four months of age. However, maternal serum retinol levels from a subset of this study population showed mean $( \pm$ SD) levels of 1.79 $( \pm 0.53)$ and $1.75( \pm 0.56) \mu \mathrm{mol} / \mathrm{L}$ in the vitamin $\mathrm{A}$ and control groups respectively, suggesting little vitamin A deficiency. The infant mortality rate in the control group (7.2 per 1000 child years) was well below that in the general population and the authors state that the families included in their study were relatively privileged (Humphrey 1996). It has been suggested that though the serum retinol levels were adequate, this finding does not preclude low hepatic reserves in this study group (Tielsch 2008a). Of the other included trials, two were conducted in India (Rahmathullah 2003) and Bangladesh (Klemm 2008), which are characterized by high infant mortality and vitamin A deficiency. The trial in India showed a reduction of $22 \%$ in the risk of infant mortality at six months whereas the trial in Bangladesh showed a $15 \%$ reduction in the vitamin A group compared with the control group. In the Indian setting, $5 \%$ to $6 \%$ of included women reported a history of night blindness, which is a clinical manifestation of vitamin A deficiency, and it was not significantly different between the two groups $(\mathrm{P}=0.26)$. The authors noted that the impact on mortality was evident from two weeks of age and continued until three months, after which no further effect was observed. Similar observations were noted in the Bangladesh trial, which reported a difference in the mortality of infants as early as after the first week of life that persisted till four months of age. There were approximately $9.5 \%$ of the pregnant women in each group who reported night blindness in their most recent pregnancy. A subsample of this study population was measured for serum retinol in the first trimester and showed a suboptimal vitamin A status (defined as 
serum retinol $<1.05 \mu \mathrm{mol} / \mathrm{L}$ ) in approximately $41 \%$ of women in the vitamin A group and $36 \%$ of women in the control group. These findings of an effect of vitamin A on the risk of mortality between the early weeks of life until four months does indicate a common biological mechanism of vitamin $\mathrm{A}$.

Conflicting results were shown by studies conducted in Nepal, Zimbabwe and Guinea Bissau. The Nepal trial (West 1995) was conducted as part of a larger vitamin A supplementation trial in preschool children. The infants supplemented in the neonatal period did not show a significant effect on infant mortality, which was evaluated at four months of age. To note, this study setting was characterized by endemic vitamin A deficiency and high infant mortality. This finding was in contrast to findings from other studies conducted in similar settings. Studies conducted in Zimbabwe (Malaba 2005) and Guinea Bissau (Benn 2008) reported non-significant effects of vitamin A on both six and 12 months infant mortality outcomes. Infant mortality was measured in the other trial by Benn et al in Guinea Bissau (Benn 2010) at 12 months, which also showed no effect on the outcome. The vitamin A status of mothers provided evidence of minimal deficiency in these study settings with mean $( \pm S D)$ serum retinol values in a subset of Zimbabwean women in the control group of $1.09( \pm 0.29)$ and $1.19( \pm 0.42) \mu \mathrm{mol} / \mathrm{L}$ at six weeks postpartum. In Guinea Bissau, less than $1 \%$ women were found to have low retinol binding proteins (retinol binding proteins $<1.11 \mu \mathrm{mol} / \mathrm{L}$ ). This study also measured serum retinol values in infants at six weeks and four months of age and showed no evidence of an effect of vitamin A supplementation on vitamin A deficiency. An important feature of this trial was that all eligible children were provided free consultations and essential drugs for any illness during the first year of life. The mechanism through which vitamin A supplementation in children older than six months of age improves survival has partly been explained by a reduction in the severity rather than the incidence of infections (Sommer 1996). We believe that provision of free consultations and essential drugs for illnesses in the Guinea Bissau trial masked any beneficial effect of vitamin A supplementation that would have occurred through reducing severe illness episodes. The reasons for possible differences in the results of vitamin A supplementation trials conducted in different geographic regions are uncertain and could be a chance observation. However, these findings could represent genuine differences in population attributable risks of micronutrient deficiencies. The studies included neonates of mothers with varying levels of baseline vitamin A deficiency, both low birth weight and normal birth weight neonates and varying rates of baseline infant mortality. These factors could affect the generalizability of study findings. It should be noted that in contrast to the observed benefits of vitamin A supplementation among mothers in Nepal (West 1999), a large trial of maternal vitamin A supplementation in Ghana (Kirkwood 2010) did not show any benefits.

Reasons for these conflicting findings are unclear and there is no clear indication of the biological mechanisms through which vitamin A could lower the risk of death when given in the neonatal period. Various mechanisms have been proposed. Newborns have marginal reserves of vitamin $\mathrm{A}$ in their liver and they depend on breast milk as a source of this vitamin in the first few months of life. Hence, low maternal vitamin A levels translate into vitamin A deficiency in the newborns (Underwood 1994). Deficiency of vitamin A could also begin very early in life with the colostrum being discarded or breastfeeding being inadequate. Colostrum and early breast milk have been found to be very rich sources of vitamin A, which can significantly augment vitamin A stores in the neonates (Wallingford 1986). Along with inadequate breastfeeding, introduction of artificial feeds also hinders with the establishment of good breastfeeding practices, thereby denying infants of this critical source of vitamin A throughout the breastfeeding period (Haskell 1999). Artificial feeds early in life also increase the risk of gastrointestinal infections in these infants. Vitamin A supplementation has also been proposed to have an impact on infant mortality through the development and maintenance of the integrity of the intestinal and respiratory epithelia, and enhanced local and systemic immunity (Sommer 1996; Tielsch 2007). These pathways may provide an explanation of the effect in settings where the practice of discarding colostrum, inadequate breastfeeding or artificial feeds and infections are common. Alternatively, the early initiation of feeding of colostrum and exclusive breastfeeding could explain an absence of a beneficial effect of vitamin A received as a supplement. However, in this review we could not study these proposed mechanisms as only a few included studies presented limited information on breastfeeding practices and the use of artificial feeds.

There has been considerable debate on the issue of supplementing neonates with vitamin A due to conflicting findings from the studies and variability in the results of pooled analyses (Abrams 2008; Bhutta 2008; Gogia 2009; Sachdev 2008; Tielsch 2008a). The current review includes data from several new studies published since these earlier reviews and additional data that were obtained by contacting the study authors. Our findings corroborate those published in the earlier Lancet Undernutrition Series (Bhutta 2008) that included three neonatal supplementation trials published until then and used available data for analysing infant mortality outcomes separately at six months and 12 months. It showed a reduction of $20 \%$ (95\% CI $4 \%$ to $34 \%$ ) in the vitamin A supplemented group compared to the unsupplemented control group at six months of age. The earlier review also showed a nonsignificant impact of vitamin A on infant mortality at 12 months of age compared to the unsupplemented control (RR 0.90; 95\% CI 0.61 to 1.32). A similar review by Gogia et al (Gogia 2009) analysed infant mortality data from six trials by pooling all deaths between the period of initiation of intervention till the last follow up, either at six or 12 months, and suggested no protective effect on mortality during the first year of life (RR 0.92; 95\% CI 0.75 to 1.12 ). We believe that such an approach would mask any bene- 
ficial effects of the intervention in early infancy and could also be influenced by routine vitamin A supplementation practices after six months of age in the given population. Given that vitamin A supplementation to infants after six months of age is relatively well established in developing countries, adjunctive benefits of neonatal vitamin A supplementation could provide complementary benefits in young infants.

Limited data were available for the outcomes of cause-specific mortality and morbidity; and vitamin A deficiency, measured as serum retinol values in infants. Data on adverse events, specifically bulging fontanelle, vomiting or diarrhoea, were also limited and showed no significant increase within the first 48 to 72 hours of supplementation. An evaluation of these outcomes is needed with the inclusion of data from all studies that have measured these outcomes and additional new trials that are being planned in Ghana (Ghana 2010), India (India 2010) and Tanzania (Tanzania 2010). These trials have been designed to evaluate the effect of 50,000 IU of vitamin A on infant mortality at six months of age, their primary outcome. Another smaller effectiveness trial in Pakistan (Pakistan 2008) has completed recruitment and follow up and the data are being analysed. These additional trials will greatly contribute towards the evidence base and consensus on the value or otherwise of neonatal vitamin A supplementation.

\section{A U THORS'CONCLUSIONS}

\section{Implications for practice}

Considering the high burden of deaths of children under the age of five years in developing countries, and mortality in infancy being a major contributory cause, it is critical to obtain sound scientific evidence of the effect of vitamin A supplementation in the neonatal period on infant mortality and morbidity. Evidence provided in this review does indicate a potential beneficial effect of supplementing neonates with vitamin A at birth in reducing mortality in the first half of infancy. Considering the absence of a clear indica- tion of the biological mechanism through which vitamin A could affect mortality in early infancy, substantial conflicting findings from individual studies in settings with potentially varying levels of maternal vitamin A deficiency and infant mortality; and given that data from at least four new trials will be available in the foreseeable future, we propose to delay any policy recommendations for neonatal vitamin A supplementation pending these findings.

\section{Implications for research}

Future research and trials should examine the effects of vitamin A supplementation in the neonatal period on infant mortality in the first half of infancy. These trials should also include measures of maternal micronutrient status (vitamin A deficiency), the effect of maternal vitamin A supplementation, dose of vitamin A, maternal HIV status, breastfeeding patterns and breast milk vitamin A concentrations. Efforts should be made to stratify effects by age after birth of vitamin A administration, prematurity and intrauterine growth retardation. Research should also be conducted to identify biologic mechanisms and indicators for vitamin A in reducing the risk of death and to explain the differences observed in vitamin A supplementation trials conducted in settings with varying levels of baseline vitamin A deficiency.

\section{ACKNOWLEDGEMENTS}

We would like to thank the trial authors who provided additional data for this review; the Cochrane Editorial Unit, particularly Toby Lasserson who provided statistical advice and drafted the summary of findings tables, Karla Soares-Weiser and Harriet MacLehose for comments on the 'Risk of bias' tables; and Furqan Bin Irfan who assisted in protocol writing. In addition, we would like to thank the staff at the editorial office of the Neonatal Cochrane Review Group for their support in the preparation of this review and, in particular, the Coordinating Editor Dr Roger Soll and Managing Editor Diane Haughton. We would also like to thank the peer reviewers who provided helpful feedback on the review.

\section{R E F E R E N C E S}

\section{References to studies included in this review}

Benn 2008 \{published data only\}

* Benn CS, Diness BR, Roth A, Nante E, Fisker AB, Lisse IM, et al. Effect of 50,000 IU vitamin A given with BCG vaccine on mortality in infants in Guinea-Bissau: randomised placebo controlled trial. BMJ 2008;336(7658): 1416-20.

Diness BR, Fisker AB, Roth A, Yazdanbakhsh M, Sartono $\mathrm{E}$, Whittle $\mathrm{H}$, et al. Effect of high-dose vitamin A supplementation on the immune response to Bacille
Calmette-Guerin vaccine. The American Journal of Clinical Nutrition 2007;86(4):1152-9.

Fisker AB, Lisse IM, Aaby P, Erhardt JG, Rodrigues A, Bibby BM, et al. Effect of vitamin A supplementation with BCG vaccine at birth on vitamin A status at $6 \mathrm{wk}$ and $4 \mathrm{mo}$ of age. The American Journal of Clinical Nutrition 2007;86 (4):1032-9.

Nante JE, Diness BR, Ravn H, Roth A, Aaby P, Benn CS. No adverse events after simultaneous administration of $50000 \mathrm{IU}$ vitamin A and Bacille Calmette-Guerin vaccination to normal-birth-weight newborns in Guinea-

Neonatal vitamin A supplementation for the prevention of mortality and morbidity in term neonates in developing countries (Review)

Copyright @ 2012 The Cochrane Collaboration. Published by John Wiley \& Sons, Ltd. 
Bissau. European Journal of Clinical Nutrition July 2008;62 (7):842-8

Benn 2010 \{published data only\}

Benn CS, Fisker AB, Napirna BM, Roth A, Diness BR, Lausch KR, et al. Vitamin A supplementation and BCG vaccination at birth in low birthweight neonates: two by two factorial randomised controlled trial. BMJ 2010;340: c1101.

Humphrey 1996 \{published data only\}

Agoestina T, Humphrey JH, Taylor GA, Usman A, Subardja D, Hidayat $S$, et al. Safety of one 52-mumol (50,000 IU) oral dose of vitamin A administered to neonates. Bulletin of the World Health Organization 1994;72(6):859-68.

Humphrey JH, Agoestina T, Juliana A, Septiana S, Widjaja $\mathrm{H}$, Cerreto MC, et al. Neonatal vitamin A supplementation: effect on development and growth at $3 \mathrm{y}$ of age. The American Journal of Clinical Nutrition 1998;68(1):109-17.

* Humphrey JH, Agoestina T, Wu L, Usman A, Nurachim $\mathrm{M}$, Subardja D, et al. Impact of neonatal vitamin A supplementation on infant morbidity and mortality. The Journal of Pediatrics 1996;128(4):489-96.

Klemm 2008 \{published data only\}

Klemm RD, Labrique AB, Christian P, Rashid M, Shamim AA, Katz J, et al. Newborn vitamin A supplementation reduced infant mortality in rural Bangladesh. Pediatrics 2008;122(1):e242-50.

Malaba 2005 \{published and unpublished data\} Humphrey JH, Iliff PJ, Marinda ET, Mutasa K, Moulton LH, Chidawanyika $\mathrm{H}$, et al. Effects of a single large dose of vitamin A, given during the postpartum period to HIVpositive women and their infants, on child HIV infection, HIV-free survival, and mortality. The Journal of Infectious Diseases 2006;193(6):860-71.

* Malaba LC, Iliff PJ, Nathoo KJ, Marinda E, Moulton LH, Zijenah LS, et al. Effect of postpartum maternal or neonatal vitamin A supplementation on infant mortality among infants born to HIV-negative mothers in Zimbabwe. The American Journal of Clinical Nutrition 2005;81(2):454-60. Miller MF, Stoltzfus RJ, Iliff PJ, Malaba LC, Mbuya NV, Zimbabwe Vitamin A for Mothers and Babies Project (ZVITAMBO) Study Group, Humphrey JH. Effect of maternal and neonatal vitamin A supplementation and other postnatal factors on anemia in Zimbabwean infants: a prospective, randomized study. The American Journal of Clinical Nutrition 2006;84(1):212-22.

Rahmathullah 2003 \{published data only\}

Coles CL, Rahmathullah L, Kanungo R, Thulasiraj RD, Katz J, Santhosham M, et al. Vitamin A supplementation at birth delays pneumococcal colonization in South Indian infants. Journal of Nutrition 2001;131(2):255-61.

* Rahmathullah L, Tielsch JM, Thulasiraj RD, Katz J, Coles C, Devi S, et al. Impact of supplementing newborn infants with vitamin A on early infant mortality: community based randomised trial in southern India. BMJ 2003;327(7409): 254.

Tielsch JM, Rahmathullah L, Thulasiraj RD, Katz J, Coles C, Sheeladevi S, et al. Newborn vitamin A dosing reduces the case fatality but not incidence of common childhood morbidities in South India. Journal of Nutrition 2007;137 (11):2470-4.

West 1995 \{published data only\}

Katz J, West KP, Khatry SK, Thapa MD, LeClerq SC, Pradhan EK, et al. Impact of vitamin A supplementation on prevalence and incidence of xerophthalmia in Nepal. Investigative Ophthalmology and Visual Science 1995;36(13): 2577-83.

* West KP Jr, Katz J, Shrestha SR, LeClerq SC, KhatrY SK, Pradhan EK, et al. Mortality of infants $<6$ mo of age supplemented with vitamin A: a randomized, doublemasked trial in Nepal. The American Journal of Clinical Nutrition 1995;62(1):143-8.

West KP, Khatry SK, LeClerq SC, Adhikari R, See L, Katz $\mathrm{J}$, et al. Tolerance of young infants to a single, large dose of vitamin A: a randomized community trial in Nepal. Bulletin of the World Health Organization 1992;70(6):733-9.

\section{References to studies excluded from this review}

Bezzera 2009 \{published data only\}

Bezerra DS, Araújo KF, Azevêdo GM, Dimenstein R. Maternal supplementation with retinyl palmitate during immediate postpartum period: potential consumption by infants. Revista de Saúde Pública 2009;43(4):572-9.

Bhaskaram 1998 \{published data only\} Bhaskaram P, Balakrishna N. Effect of administration of 200,000 IU of vitamin A to women within $24 \mathrm{hrs}$ after delivery on response to PPV administered to the newborn. Indian Pediatrics 1998;35(3):217-22.

\section{References to ongoing studies}

Ghana 2010 \{published data only\}

Efficacy of newborn vitamin A supplementation in improving child survival in rural Ghana: generation of evidence necessary for informing global policy (Neovita). Ongoing study Anticipated date of first participant enrolment: Aug 16, 2010.

India 2010 \{published data only\} Efficacy of Neonatal Vitamin A Supplementation in Improving Child Survival in Haryana, India: Generation of Evidence Necessary for Informing Global Policy (NeoVitA Trial). Ongoing study June 2010.

Pakistan 2008 \{published data only\} Feasibility study of delivering a neonatal dose of vitamin A through the Lady Health Workers (LHWs) program in Pakistan. Ongoing study January 2007.

Tanzania 2010 \{published data only\} Efficacy of newborn vitamin A supplementation in improving child survival in Tanzania: generation of evidence necessary for informing global policy. Ongoing study Anticipated date of first participant enrolment: July $1,2010$.

\section{Additional references}

Neonatal vitamin A supplementation for the prevention of mortality and morbidity in term neonates in developing countries (Review) 


\section{Abrams 2008}

Abrams SA, Hilmers DC. Postnatal vitamin A supplementation in developing countries: an intervention whose time has come?. Pediatrics 2008;122(1):180-1.

Beaton 1993

Beaton GH, Martorell R, Aronson KJ, Edmonston B, McCabe G, Ross AC, et al. Effectiveness of vitamin A supplementation in the control of young child morbidity and mortality in developing countries. ACC/SCN State-ofthe-Art Series policy discussion paper no. 13. World Health Organization, Geneva, Switzerland 1993.

\section{Bhutta 2008}

Bhutta ZA, Ahmed T, Black RE, Cousens S, Dewey K, Giugliani E, et al. What works? Interventions for maternal and child undernutrition and survival. Lancet 2008;371 (9610):417-40.

\section{Daulaire 1992}

Daulaire NM, Starbuck ES, Houston RM, Church MS, Stukel TA, Pandey MR. Childhood mortality after a high dose of vitamin A in a high risk population. BMJ 1992;304 (6821):207-10

\section{DRI 2001}

Dietary Reference Intakes for Vitamin A, Vitamin K, Arsenic, Boron, Chromium, Copper, Iodine, Iron, Manganese, Molybdenum, Nickel, Silicon, Vanadium, and Zinc. The National Academies 2001.

\section{Gogia 2009}

Gogia S, Sachdev HS. Neonatal vitamin A supplementation for prevention of mortality and morbidity in infancy: systematic review of randomised controlled trials. $B M J$ 2009;338:b919.

\section{Haskell 1999}

Haskell MJ, Brown KH. Maternal vitamin A nutriture and the vitamin A content of human milk. Journal of Mammary Gland Biology and Neoplasia 1999;4(3):243-57.

\section{Hathcock 1997}

Hathcock JN. Vitamins and minerals: efficacy and safety. The American Journal of Clinical Nutrition 1997;66(2): $427-37$.

\section{Hopkins 1912}

Hopkins FG. Feeding experiments illustrating the importance of accessory factors in normal dietaries. The Journal of Physiology 1912;44(5-6):425-60.

Huiming 2005

Huiming Y, Chaomin W, Meng M. Vitamin A for treating measles in children. Cochrane Database of Systematic Reviews 2005, Issue 4. [DOI: 10.1002/ 14651858.CD001479.pub3]

Imdad 2010

Imdad A, Herzer K, Mayo-Wilson E, Yakoob MY, Bhutta ZA. Vitamin A supplementation for preventing morbidity and mortality in children from 6 months to 5 years of age. Cochrane Database of Systematic Reviews 2010, Issue 12. Art. No.: CD008524.. [DOI: 10.1002/ 14651858.CD008524.pub2]

\section{Kirkwood 2010}

Kirkwood BR, Hurt L, Amenga-Etego S, Tawiah C, Zandoh C, Danso S, et al. Effect of vitamin A supplementation in women of reproductive age on maternal survival in Ghana (ObaapaVitA): a cluster-randomised, placebo-controlled trial. Lancet 2010;375(9726):1640-9.

\section{McCollum 1915}

McCollum EV, Davis M. The influence of certain vegetable fats on growth. Journal of Biochemistry 1915;21:179-82.

Rahman 1995

Rahman MM, Mahalanabis D, Wahed MA, Islam MA, Habte D. Administration of 25,000 IU vitamin A doses at routine immunisation in young infants. European Journal of Clinical Nutrition 1995;49(6):439-45.

\section{Rice 2004}

Rice AL, West KP Jr, Black RE. Vitamin A deficiency. Global and regional burden of disease attributable to selected major risk factors. Vol. 1, Geneva: World Health Organization, 2004.

Sachdev 2008

Sachdev HP. Neonatal vitamin A supplementation and infant survival in Asia. Lancet 2008;371(9626):1746; author reply 1746-8.

Shenai 1993

Shenai JP. Vitamin A. In: Tsang RC, Lucas A, Uauy R editor(s). Nutritional needs of the preterm infant: scientific basis and practical guidelines. Baltimore: Williams and Williams, 1993:87-100.

\section{Smith 1976}

Smith FR, Goodman DS. Vitamin A transport in human vitamin A toxicity. New England Journal of Medicine 1976; 294(15):805-8.

\section{Sommer 1995}

Sommer A. Vitamin A deficiency and its consequences: a field guide to their detection and control. 3rd ed Geneva: World Health Organization 1995.

Sommer 1996

Sommer A, West KP Jr. Vitamin A deficiency: health, survival, and vision. New York: Oxford University Press, 1996

Sommer 2002

Sommer A, Davidson FR. Assessment and control of vitamin A deficiency: the Annecy Accords. Journal of Nutrition 2002;132 Suppl(9):2845-50

\section{SOWC 1998}

United Nations Children's Fund. State of the World's Children. Oxford University, 1998.

\section{Sugana 1978}

Sugana T, Sommer A. Prevention of neonatal blindness. Lancet 1978;2(8099):1101 (letter).

Tielsch 2007

Tielsch JM, Rahmathullah L, Thulasiraj RD, Katz J, Coles C, Sheeladevi S, et al. Newborn vitamin A dosing reduces the case fatality but not incidence of common childhood 
morbidities in South India. Journal of Nutrition 2007;137 (11):2470-4.

\section{Tielsch 2008a}

Tielsch JM. Vitamin A supplements in newborns and child survival. BMJ 2008;336(7658):1385-6.

\section{Underwood 1994}

Underwood BA. Maternal vitamin A status and its importance in infancy and early childhood. The American Journal of Clinical Nutrition 1994;59 Suppl(2):517-24.

\section{Wallingford 1986}

Wallingford JC, Underwood BA. Vitamin A deficiency in pregnancy, lactation, and the nursing child. Vitamin $A$ deficiency and its control. Bauernfeind IC, ed.. New York: Academic Press, 1986:101-52.

\section{West 1999}

West KP Jr, Katz J, Khatry SK, LeClerq SC, Pradhan EK, Shrestha SR, et al. Double blind, cluster randomised trial of low dose supplementation with vitamin A or beta carotene on mortality related to pregnancy in Nepal. The NNIPS-2 Study Group. BMJ 1999;318(7183):570-5.

\section{WHO 1998}

Global Programme for Vaccines and Immunizations. Integration of vitamin A supplementation with immunization: policy and programme implications. Geneva: World Health Organization (WHO/EPI/GEN/ 98.07) 1998.

\section{WHO 2000}

World Health Organization. Nutrition for health and development. WHO/NHD/00 6: WHO, Geneva, Switzerland 2000

\section{WHO 2009}

World Health Organization. Global Prevalence of Vitamin A Deficiency in Populations at Risk 1995-2005. WHO Global Database on Vitamin A Deficiency. Geneva, Switzerland 2009.

\section{WHO/CHD 1998}

WHO/CHD Immunization-Linked Vitamin A

Supplementation Study Group. Randomized trial to assess benefits and safety of vitamin A supplementation linked to immunization in early infancy. Lancet 1998;352(9136):

1257-63.

\section{WHO/NUT 1998}

Safe vitamin A dosage during pregnancy and lactation. Geneva, World Health Organization, 1998 (WHO/NUT/ 98.4).

\section{WHO/NUT/98.1 1998}

Complementary feeding of young children in developing countries: a review of current scientific knowledge. Geneva, World Health Organization, 1998 (WHO/NUT/98.1).

\section{Wolbach 1925}

Wolbach SB, Howe PR. Tissue changes following deprivation of fat-soluble vitamin A. Journal of Experimental Medicine 1925;42(6):753-77.

* Indicates the major publication for the study 


\section{CHARACTERISTICS OF STUDIES}

\section{Characteristics of included studies [ordered by study ID]}

\section{Benn 2008}

\begin{tabular}{|c|c|}
\hline Methods & Randomised, double blind placebo controlled trial. \\
\hline Participants & $\begin{array}{l}\text { Inclusion criteria were infants weighing at least } 2500 \mathrm{~g} \text { at birth with no signs of overt } \\
\text { illness or malformations. Infants were recruited at the time of BCG vaccination. Number } \\
\text { of participants in vitamin A group was } 2145 \text { and that in the placebo was } 2200\end{array}$ \\
\hline Interventions & $\begin{array}{l}0.5 \mathrm{ml} \text { vegetable oil, either containing } 50,000 \mathrm{IU} \text { of vitamin A as retinyl palmitate and } \\
10 \mathrm{IU} \text { vitamin } \mathrm{E} \text {, or only } 10 \mathrm{IU} \text { of vitamin } \mathrm{E} \text { was given into the mouth of child at the } \\
\text { time of BCG vaccination }\end{array}$ \\
\hline Outcomes & $\begin{array}{l}\text { Mortality at } 12 \text { month of age, cause specific mortality at } 12 \text { months of age, scar, in } \\
\text { vivo and ex vivo PPD response to BCG, retinol binding protein (RBP) concentration } \\
\text { at } 6 \text { weeks and } 4 \text { months of age (low RBP defined as serum retinol }<0.70 \text { micromol/ } \\
\text { L) and adverse effects (bulging fontanelle, hospitalizations, irritability, fever, frequent } \\
\text { stools, vomiting, mother thinks the child is not well) }\end{array}$ \\
\hline Notes & $\begin{array}{l}\text { Study was conducted in } 6 \text { urban districts in capital of Guinea-Bissau which is classified } \\
\text { as an area of subclinical vitamin A deficiency (by UNICEF) and high infant mortality. } \\
\text { The HIV prevalence among women in the study area was 3-5\% } \\
\text { Since the authors did not have information about the gestational age at delivery and the } \\
\text { inclusion criteria was infants with birth weight of at least } 2500 \mathrm{~g} \text {, we included data as } \\
\text { such in the term neonate analysis assuming that a greater proportion of these were term } \\
\text { infants }\end{array}$ \\
\hline
\end{tabular}

Risk of bias

\begin{tabular}{|c|c|c|}
\hline Bias & Authors' judgement & Support for judgement \\
\hline $\begin{array}{l}\text { Random sequence generation (selection } \\
\text { bias) }\end{array}$ & Low risk & $\begin{array}{l}\text { Quote: "mother drew a lot from an enve- } \\
\text { lope prepared by the study supervisor. Each } \\
\text { envelope contained } 100 \text { lots } 50 \text { marked " } 1 \text { " } \\
\text { and } 50 \text { marked " } 2 \text { " indicating from which } \\
\text { of two numbered bottles, " } 1 \text { " or " } 2 \text {," the } \\
\text { child should receive the supplement" } \\
\text { Comment: probably done }\end{array}$ \\
\hline Allocation concealment (selection bias) & Low risk & $\begin{array}{l}\text { Quote: "lots were folded, making it impos- } \\
\text { sible to tell what was written on them before } \\
\text { they were opened. A new envelope was not } \\
\text { taken into use before the previous envelope } \\
\text { had been completely emptied. The result } \\
\text { of the randomisation was noted on the in- } \\
\text { clusion form and the lot was stapled to the } \\
\text { inclusion form.", "The dark glass bottles }\end{array}$ \\
\hline
\end{tabular}

Neonatal vitamin A supplementation for the prevention of mortality and morbidity in term neonates in developing countries (Review) 21 Copyright $\odot 2012$ The Cochrane Collaboration. Published by John Wiley \& Sons, Ltd. 


\begin{tabular}{|c|c|c|}
\hline & & $\begin{array}{l}\text { were prepared at Skanderborg Pharmacy" } \\
\text { and "The code was kept at the pharmacy } \\
\text { until } 12 \text { months after the last child was in- } \\
\text { cluded" } \\
\text { Comment: probably done }\end{array}$ \\
\hline $\begin{array}{l}\text { Blinding (performance bias and detection } \\
\text { bias) } \\
\text { All outcomes }\end{array}$ & Low risk & $\begin{array}{l}\text { Quote: "blinding of mothers and assistants } \\
\text { was successful" and "assistants of the reg- } \\
\text { istration system and the special team were } \\
\text { unaware........vaccination card and follow } \\
\text { up forms" and "Apart from the randomi- } \\
\text { sation number, the bottles looked alike; we } \\
\text { judged small differences in taste and colour } \\
\text { of the contents as unimportant owing to } \\
\text { the recipients" } \\
\text { Comment: blinding of participants, study } \\
\text { personnel and outcome assessors probably } \\
\text { done }\end{array}$ \\
\hline $\begin{array}{l}\text { Incomplete outcome data (attrition bias) } \\
\text { All outcomes }\end{array}$ & Low risk & $\begin{array}{l}\text { Attrition was } 1.6 \% \text {. Reasons for attrition } \\
\text { and distribution in the two groups were } \\
\text { provided. Infant lost to follow up were sim- } \\
\text { ilar to those who were followed in baseline } \\
\text { anthropometric characteristics }\end{array}$ \\
\hline Selective reporting (reporting bias) & Low risk & $\begin{array}{l}\text { Comment: results of all expected outcomes } \\
\text { were presented in several publications of } \\
\text { the study }\end{array}$ \\
\hline Other bias & High risk & $\begin{array}{l}\text { A protocol was provided but post hoc anal- } \\
\text { yses were conducted after assuming that } \\
\text { Vit A might be more beneficial to boys. } \\
\text { The study was funded by the EU (ICA4- } \\
\text { CT-2002-10053), the Danish Medical Re- } \\
\text { search Council, University of Copenhagen, } \\
\text { March of Dimes, and the Ville Heise Foun- } \\
\text { dation }\end{array}$ \\
\hline
\end{tabular}

Benn 2010

Methods

Participants

Interventions
Randomised, placebo controlled, two by two factorial trial.

Inclusion criteria were infants weighing $<2500 \mathrm{~g}$ at birth with no severe malformations. Number of participants in vitamin A group was 864 and that in the placebo was 872

Neonates $<2500 \mathrm{~g}$ at birth were assigned to 25,000 IU vitamin A as retinyl palmitate and $10 \mathrm{IU}$ vitamin $\mathrm{E}$ per $0.5 \mathrm{ml}$ oil or placebo which contained only $10 \mathrm{IU}$ vitamin E per $0.5 \mathrm{ml}$ oil, as well as to early BCG vaccine or the usual late BCG vaccine 
Benn 2010 (Continued)

\begin{tabular}{|c|c|}
\hline Outcomes & Infant mortality and cause-specific infant mortality at 12 months \\
\hline Notes & $\begin{array}{l}\text { - Study was conducted in } 6 \text { urban districts in capital of Guinea-Bissau which is } \\
\text { classified as an area having moderate to severe vitamin A deficiency (by WHO) and } \\
\text { high infant mortality. } \\
\text { - No evidence of an interaction between BCG and vitamin A supplementation in } \\
\text { neonates ( } \mathrm{P}=0.73 \text { ). } \\
\text { - Vitamin A was administered within the first } 48 \text { hours of life to } 878(51 \%) \text { of the } \\
1717 \text { children. }\end{array}$ \\
\hline
\end{tabular}

\section{Risk of bias}

\begin{tabular}{|c|c|c|}
\hline Bias & Authors' judgement & Support for judgement \\
\hline $\begin{array}{l}\text { Random sequence generation (selection } \\
\text { bias) }\end{array}$ & Low risk & $\begin{array}{l}\text { Quote: "randomly allocated in a two by } \\
\text { two factorial design" and"mother drew an } \\
\text { envelope } \\
\text { from a bag. Each bag was prepared... } 12 \\
\text { marked "no BCG } 6 \text {," and } 12 \text { marked "no } \\
\text { BCG 7", "The numbers } 6 \text { and } 7 \text { indicated } \\
\text { from which of two numbered bottles, } 6 \text { or } \\
7 \text {, the child should receive treatment (that } \\
\text { is, either } 25000 \text { IU vitamin A or placebo) } \\
\text { " } \\
\text { Comment: probably done }\end{array}$ \\
\hline
\end{tabular}

Allocation concealment (selection bias) Low risk

Quote: "The envelopes were closed and non-transparent, making it impossible to identify the allocation before the envelopes were opened.", "The result of the randomisation was noted on the inclusion form and, furthermore, the lot name was stapled on the form." and "The code of which treatment was in which bottle was kept at the pharmacy until 12 months after the last child was included.“

Comment: probably done

Blinding (performance bias and detection Low risk bias)

All outcomes
Quote: "numbers "6" and " 7 " indicated from which of two numbered bottles, " 6 " or " 7 ," the child should receive treatment", "vitamin A and placebo bottles looked alike" and "assistant and the nurse who were responsible for the randomisation procedures had no idea which bottles contained vitamin A or which had placebo" and "follow-up assistants were unaware of the allocated treatment, 


\begin{tabular}{l|l|l} 
& & $\begin{array}{l}\text { Comment: blinding of participants, study } \\
\text { personnel and outcome assessors probably } \\
\text { done }\end{array}$ \\
\hline $\begin{array}{l}\text { Incomplete outcome data (attrition bias) } \\
\text { All outcomes }\end{array}$ & Low risk & $\begin{array}{l}\text { Exclusions and attrition were 18.72\%. Rea- } \\
\text { sons and distribution in the two groups } \\
\text { were provided. Numbers were balanced } \\
\text { across the treatment groups }\end{array}$ \\
\hline Selective reporting (reporting bias) & Low risk & $\begin{array}{l}\text { Comment: All expected outcomes, as per } \\
\text { protocol were reported or are under prepa- } \\
\text { ration (personal communication from the } \\
\text { author) }\end{array}$ \\
\hline Other bias & High risk & $\begin{array}{l}\text { A protocol was provided but post hoc anal- } \\
\text { yses were conducted after assuming that } \\
\text { Vit A might be more beneficial to boys. } \\
\text { The study was funded by the EU (ICA4- } \\
\text { CT-2002-10053), the Danish Medical Re- } \\
\text { search Council, University of Copenhagen, } \\
\text { March of Dimes, and the Ville Heise Foun- } \\
\text { dation }\end{array}$ \\
\hline
\end{tabular}

\section{Humphrey 1996}

\begin{tabular}{l|l}
\hline Methods & Randomised placebo controlled trial. \\
\hline Participants & $\begin{array}{l}\text { All neonates within } 24 \text { hours of birth were eligible for inclusion. Very low birthweight } \\
\text { babies }(<1500 \mathrm{gm}) \text { and those with life threatening illnesses such as severe respiratory } \\
\text { distress syndrome, major congenital anomalies, paralysis, hypoglycaemia, hypocalcaemia, } \\
\text { clinical evidence of ischaemic hypoxia, or sepsis were excluded. A total of } 2067 \text { were } \\
\text { enrolled within the } 24-\text { hour inclusion period }\end{array}$ \\
\hline Interventions & $\begin{array}{l}\text { One oral dose of } 52 \mu \text { mol vitamin A (as retinyl palmitate) plus } 23 \mu \text { mol vitamin E in the } \\
\text { treatment group. Placebo }(<0.10 \mu \text { mol vitamin A }+23 \mu \text { mol vitamin E) in the control } \\
\text { group. Intervention n=1034 and placebo n=1033 }\end{array}$ \\
\hline Outcomes & $\begin{array}{l}\text { Mortality at } 6 \text { and } 12 \text { months of age, cause specific mortality at } 12 \text { month of age, } \\
\text { morbidity at } 4 \text { months of age, adverse effects of VAS (bulging fontanelle, vomiting, } \\
\text { fever, loose stool, irritability, intracranial haemorrhage, resistive index), development at } \\
3 \text { years of age }\end{array}$ \\
\hline Notes & $\begin{array}{l}\text { - Infants born at Hasan Sadikin Hospital in Bandung, Indonesia, from June } 18, \\
1992 \text { to June } 3,1993 \text { were considered. } \\
\text { of life birth. } \\
\text { Treatment groups were comparable at baseline. }\end{array}$ \\
\hline
\end{tabular}


Humphrey 1996 (Continued)

\section{Risk of bias}

\begin{tabular}{|c|c|c|}
\hline Bias & Authors' judgement & Support for judgement \\
\hline $\begin{array}{l}\text { Random sequence generation (selection } \\
\text { bias) }\end{array}$ & Unclear risk & $\begin{array}{l}\text { Quote: "simple randomisation blocked within } \\
\text { the birth weight strata" } \\
\text { Comment: method used to generate the ran- } \\
\text { domisation sequence is not described in suff- } \\
\text { cient detail to permit judgement }\end{array}$ \\
\hline Allocation concealment (selection bias) & Low risk & $\begin{array}{l}\text { Quote: "The randomisation scheme and coded } \\
\text { supplement packets were prepared by a team in } \\
\text { Baltimore, none of whom was involved in re- } \\
\text { cruitment or follow-up of infants in Indonesia" } \\
\text { Comment: probably done }\end{array}$ \\
\hline $\begin{array}{l}\text { Blinding (performance bias and detection } \\
\text { bias) } \\
\text { All outcomes }\end{array}$ & Low risk & $\begin{array}{l}\text { Quote: "supplements were individually coded, } \\
\text { odourless......follow-up of infants in Indonesia" } \\
\text { Comment: blinding of participants, study per- } \\
\text { sonnel and outcome assessors probably done }\end{array}$ \\
\hline $\begin{array}{l}\text { Incomplete outcome data (attrition bias) } \\
\text { All outcomes }\end{array}$ & Low risk & $\begin{array}{l}\text { Attrition was } 11 \% \text { and reasons for it were pro- } \\
\text { vided. Distribution was balanced in the two } \\
\text { groups. Infants lost to follow up were not signif- } \\
\text { icantly different from those who were followed }\end{array}$ \\
\hline Selective reporting (reporting bias) & Unclear risk & $\begin{array}{l}\text { Comment: Insufficient information to permit } \\
\text { judgement } \\
\text { Adverse events were reported in a separate pub- } \\
\text { lication (Agoestina 1994) }\end{array}$ \\
\hline Other bias & Unclear risk & $\begin{array}{l}\text { Agoestina } 1994 \text { mentioned a protocol, but no } \\
\text { further details were provided. Supported by a } \\
\text { grant from John HopkinsUniversity and assis- } \\
\text { tance from Hoffmann-LaRoche industry (Basel, } \\
\text { Switzerland) }\end{array}$ \\
\hline
\end{tabular}

Klemm 2008

Methods

Participants
Community based double masked, cluster randomised, placebo controlled trial

Infants born to consenting mothers who were participating in the parent trial were eligible for inclusion in the study

Vitamin A group infants whose mothers consented $=8525$

Placebo group infants whose mothers consented $=8591$

Infants of consenting mothers who had died before they could be supplemented by staff, those who were born outside of the study area, and infants who could not be reached to 


\begin{tabular}{l|l}
\hline Interventions & $\begin{array}{l}\text { receive a supplement after repeated staff visits during the first } 30 \text { days after birth were } \\
\text { excluded }\end{array}$ \\
\hline Outcomes & $\begin{array}{l}\text { Intervention }=50,000 \text { IU of vitamin A or a placebo in oil given as soon as possible after } \\
\text { birth }\end{array}$ \\
\hline Notes & Infant mortality at 6 months of age and adverse effects \\
\hline $\begin{array}{l}\text { - The trial was nested into an ongoing, placebo controlled, weekly, low-dose } \\
\text { vitamin A or beta-carotene supplementation trial among pregnant women, underway } \\
\text { since August } 2001 \text {, to evaluate effects on pregnancy related mortality. The present } \\
\text { study began in January } 2004 \text { in districts of Gaibandha and Rangpur, Bangladesh. } \\
\text { - Randomisation of sectors was done in a manner to produce } 2 \text { infant }\end{array}$ \\
$\begin{array}{l}\text { supplementation groups that were balanced across the maternal supplementation trial } \\
\text { arms. Interaction between maternal and vitamin A supplementation was non- } \\
\text { significant. } \\
\text { - Approx } 84 \% \text { supplemented within the first } 48 \text { hours after birth. } \\
\text { - Treatment groups were comparable at baseline. } \\
\text { - Analysis was adjusted for cluster design. }\end{array}$ \\
\hline
\end{tabular}

\section{Risk of bias}

\begin{tabular}{|c|c|c|}
\hline Bias & Authors' judgement & Support for judgement \\
\hline $\begin{array}{l}\text { Random sequence generation (selection } \\
\text { bias) }\end{array}$ & Unclear risk & $\begin{array}{l}\text { Quote: "cluster randomised" and "sectors } \\
\text { were listed in geographically contiguous or- } \\
\text { der and were randomised in blocks of } 4 \text { " } \\
\text { Comment: method used to generate the } \\
\text { randomisation sequence is not described in } \\
\text { sufficient detail to permit judgement }\end{array}$ \\
\hline Allocation concealment (selection bias) & Unclear risk & $\begin{array}{l}\text { Comment: insufficient detail to permit } \\
\text { judgement. }\end{array}$ \\
\hline
\end{tabular}

Blinding (performance bias and detection Low risk bias)

All outcomes
Quote: "sector-coded supplement”, “supplements for both groups were opaque gelatinous capsules identical in shape, size, and colour containing edible oil"; "doublemasked"

Comment: blinding of participants, study personnel and outcome assessors probably done

Incomplete outcome data (attrition bias) Low risk All outcomes
Exclusions and attrition was 7\%. Reasons and distribution in the two groups were provided. Attrition and reasons for attrition were balanced across the treatment groups 
Selective reporting (reporting bias) Low risk
High risk
Comment: results of all outcomes mentioned in methods section of the published paper and those in trial registration document were presented in the paper

Study halted before conclusion because mortality on the placebo group was significantly higher than intervention group after $2 / 3$ of infants were randomised. Results adjusted by cluster effect. Source of funding: John Hopkins University (GHS-A-00-0300019-00), Bill and Melinda Gates Foundation

Malaba 2005

\begin{tabular}{|c|c|}
\hline Methods & Randomised placebo controlled two by two factorial design trial \\
\hline Participants & $\begin{array}{l}\text { Mother and infant pairs enrolled within } 96 \text { hrs of delivery. Pairs were eligible if neither } \\
\text { of the pairs have an acutely life threatening condition, the infant was a singleton with } \\
\text { birthweight }>1500 \text { gms, and the mother planned to stay in Harare after delivery } \\
\text { Mothers and infants were assigned into the following } 4 \text { groups } \\
1 . \text { Mothers received } 400,000 \text { IU vitamin A and infants received } 50000 \text { IU vitamin } \\
\text { A (Aa group) }=3529 \\
\text { 2. Mothers received } 400,000 \text { IU vitamin A and infants received placebo } \\
\text { (Ap group) }=3529 \\
\text { 3. Mothers received placebo and infants received 50,000 IU vitamin A } \\
\text { (Pa group) }=3530 \\
\text { 4. Both mothers and infants received placebo } \\
\text { (Pp group) }=3522\end{array}$ \\
\hline Interventions & $\begin{array}{l}\text { Mothers received } 400,000 \text { IU vitamin A and infants received 50,000 IU vitamin A. Both } \\
\text { treatment and placebo contained a soy oil base with vitamin E ( } 50 \text { IU per maternal } \\
\text { capsule; } 10 \text { IU per infant capsule). }\end{array}$ \\
\hline Outcomes & $\begin{array}{l}\text { Infant mortality at } 6 \text { and } 12 \text { months, cause-specific infant mortality at } 12 \text { months, } \\
\text { anaemia and haemoglobin in infants and MTCT of HIV in infants born to HIV positive } \\
\text { mothers }\end{array}$ \\
\hline Notes & $\begin{array}{l}\text { - Zimbabwe is categorized by WHO as a high risk area for vitamin A deficiency. } \\
\text { HIV is endemic in Zimbabwe nearly } 25 \% \text { are HIV infected. } \\
\text { - From } 25 \text { November } 1997 \text { to } 29 \text { January } 2000 \text { in Harare, Zimbabwe. } \\
\text { - Three-quarters of the pairs received their treatment dose within } 24 \text { hours, and } \\
94 \% \text { received it within } 48 \text { hours of delivery. } \\
\text { - Interaction between maternal and infant vitamin A supplementation was not } \\
\text { significant }(\mathrm{P}=0.60) \text {. }\end{array}$ \\
\hline
\end{tabular}

\section{Risk of bias}

Neonatal vitamin A supplementation for the prevention of mortality and morbidity in term neonates in developing countries (Review) 


\begin{tabular}{|c|c|c|}
\hline Bias & Authors' judgement & Support for judgement \\
\hline $\begin{array}{l}\text { Random sequence generation (selection } \\
\text { bias) }\end{array}$ & Low risk & $\begin{array}{l}\text { Quote: "study identification numbers were } \\
\text { randomly allocated to the treatment groups } \\
\text { by computer in blocks of } 12 \text { ", "A separate } \\
\text { team at Johns Hopkins University prepared } \\
\text { the study capsule packets" and "Lists link- } \\
\text { ing the study number to the treatment were } \\
\text { kept in sealed envelopes and encrypted } \\
\text { computer files." } \\
\text { Comment: probably done. }\end{array}$ \\
\hline
\end{tabular}

Allocation concealment (selection bias) Low risk

Blinding (performance bias and detection Low risk bias)

All outcomes
Quote: "numbers were printed on adhesive labels and affixed to amber-coloured ziplock plastic bags" and "capsules in the next sequential bag were administered...... files" Comment: probably done.

\begin{tabular}{|l} 
"neither participants nor nurses who ad- \\
ministered the capsules or assessed out- \\
comes were aware of treatment group as- \\
signment" \\
Comment: blinding of participants, study \\
personnel and outcome assessors probably \\
done
\end{tabular}

Incomplete outcome data (attrition bias) Unclear risk All outcomes
Quote: "capsules appeared identical”; "separate team at Johns Hopkins University prepared the study capsule packets" and "neither participants nor nurses who administered the capsules or assessed outwere aware of treatment group assignment" personnel and outcome assessors probably done

Exclusions and attrition were $41.8 \%$. Reasons for exclusion included being HIV-positive or HIV-indeterminate at baseline or those who seroconverted. Reasons for attrition were not provided

Selective reporting (reporting bias) Low risk

Low risk
Comment: results of all expected outcomes were presented in various publications

"The ZVITAMBO Project was primarily supported by the Canadian International Development Agency (R/C Project 690/ M3688), the US Agency for International Development (cooperative agreement no. HRN-A-00-97-00015-00 between Johns Hopkins University and the Office of Health and Nutrition of the USAID), and a grant from the Bill and Melinda Gates Foundation (Seattle); additional support 
was provided by the Rockefeller Foundation (New York) and BASF (Ludwigshafen, Germany).”

Rahmathullah 2003

Methods

Participants

Outcomes

Notes
Randomised, placebo controlled, community based trial.

Live born infants that resulted from all pregnancies within participating villages were eligible for participation. Pregnant women ( $>12$ weeks) were identified for recruitment from a variety of sources. The infants were randomly assigned to receive either the intervention, or placebo

Exclusions after randomisation were stillbirths, miscarriages, delivery more than $20 \mathrm{~km}$ outside the study area, and infants, who died before the study team reached

Infants received $24,000 \mathrm{IU}$ of vitamin A twice within a 24 hour interval, beginning within 48 hours of birth, or placebo

Infant mortality at 6 months, cause-specific mortality at 6 months, incidence of common morbidities and pneumococcal colonization

- Conducted between June 1998 and March 2001 in two rural districts of Tamil Nadu, southern India.

- These areas are characterized by endemic vitamin A deficiency.

- An expected infant mortality at 6 months of age of 52.5 per 1000 live births.

- Approximately $80 \%$ of participants were supplemented within 48 hours of birth.

- Treatment groups were comparable at baseline.

\section{Risk of bias}

Bias

Random sequence generation (selection Unclear risk bias)
Authors' judgement

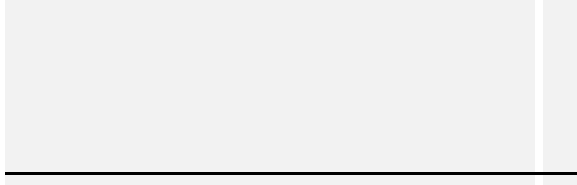

Allocation concealment (selection bias)
Unclear risk

\section{Support for judgement}

Quote: "randomisation was at the individual level, stratified by geographical area in blocks of four."

Comment: method used to generate the randomisation sequence is not described in sufficient detail to permit judgement

Quote: "For twins, the first born received the assigned treatment and the second born the other treatment. For triplets, the first two born infants were handled as twins and the third born received the originally assigned treatment."

Comment: insufficient information provided to judge allocation concealment for singleton births. However, for triplets (only 
2 in the data set), allocation concealment did not hold

Blinding (performance bias and detection Low risk bias)

All outcomes
Quote: "treatment doses were in an edible oil solution packaged in identical gelatin capsules" and "investigators, study staff, and mothers were masked to the assigned treatment"

Comment: blinding of participants, study personnel and outcome assessors was probably done

Incomplete outcome data (attrition bias) Low risk All outcomes

Unclear risk

Exclusions and attrition was $18.9 \%$. Reasons and distributions in the two treatment groups were reported. Mortality in infants born alive but not enrolled was similar in treatment groups

Comment: outcomes mentioned in the methods section were reported. All expected outcomes were presented in published reports

Other bias
Supported by a grant from John Hopkins Universityand the Bill and Melinda Gates Foundation

\section{West 1995}

Methods

Participants

Interventions

Outcomes
This trial was part of a large, cluster randomised, double masked, placebo controlled community trial in Nepal

\begin{tabular}{l|l} 
Interventions & $\begin{array}{l}\text { Intervention group received an oral dose of vitamin A [15,000 RE (50,000 IU) in } 3 \\
\text { drops of oil for neonates ( }<1 \text { mo of age) and } 30,000 \mathrm{RE}(100000 \mathrm{IU}) \text { in } 6 \mathrm{drops} \text { of oil } \\
\text { for infants } 1-5 \text { mo of age or placebo [75 RE ( } 250 \mathrm{IU}) \text { or } 150 \mathrm{RE}(500 \mathrm{IU}) \text {, respectively]. } \\
\text { A total of } 11,918 \text { infants (infants } \leq 5 \text { months: intervention= } 6086, \text { control=5832) were } \\
\text { enrolled. Among these, the distribution of neonates was: intervention=791, control= } \\
830\end{array}$ \\
\hline Outcomes & $\begin{array}{l}4 \text { month mortality, cause specific mortality and adverse effect noted after } 24 \text { hours of } \\
\text { dosing (vomiting, loose stools, fever, irritability, bulging fontanelles) }\end{array}$ \\
\hline Notes & $\begin{array}{l}\text { - Was conducted in district of Sarlahi, Nepal between September } 1989 \text { and } \\
\text { December } 1991 . \\
\text { - Evaluated the effect of VAS every } 4 \text { month on preschool child mortality. } \\
\text { - No information about gestational age and birth weight recorded and almost all } \\
\text { neonates were supplemented after the first week of life (Keith West; personnel }\end{array}$
\end{tabular}


West 1995 (Continued)

communication 2008)

- Treatment groups were comparable at baseline.

- The 4-month mortality estimates have been included in the 6 month mortality analysis

- This trial measured adverse effects approximately 24 hours after supplementation whereas 2 other trials reported adverse effects 48-72 hours after supplementation. Because of the difference in the timing of measurement of adverse effects, we did not include the 24 hour measurements from this trial in the analysis. This trial found no difference in the incidence of various adverse effects after 24 hours of supplementation in the two groups of neonates.

\section{Risk of bias}

\begin{tabular}{|c|c|c|}
\hline Bias & Authors' judgement & Support for judgement \\
\hline $\begin{array}{l}\text { Random sequence generation (selection } \\
\text { bias) }\end{array}$ & Unclear risk & $\begin{array}{l}\text { Quote: "Two hundred sixty-one wards in } \\
29 \text { contiguous village development areas } \\
\text { (VDAs) in the District of Sanlahi were } \\
\text { mapped and } 33,000 \text { households were num- } \\
\text { bered. After a random start, wards were sys- } \\
\text { tematically assigned, blocked on VDAs, for } \\
\text { infants to receive an oral dose of vitamin A. } \\
\text { " } \\
\text { Comment: method used for the first ran- } \\
\text { dom assignment is not described in suff- } \\
\text { cient detail to permit judgement }\end{array}$ \\
\hline Allocation concealment (selection bias) & Unclear risk & $\begin{array}{l}\text { Comment: It is unclear as the wards were } \\
\text { assigned systematically }\end{array}$ \\
\hline $\begin{array}{l}\text { Blinding (performance bias and detection } \\
\text { bias) } \\
\text { All outcomes }\end{array}$ & Low risk & $\begin{array}{l}\text { Quote: "gelatinous capsules of identical ap- } \\
\text { pearance, size }\left(8^{*} 16 \mathrm{~mm}\right) \text {, and taste" and } \\
\text { "double-masked" and "capsule codes were } \\
\text { broken" (noted from methods section of } \\
\text { the larger trial paper) } \\
\text { Comment: blinding of participants, study } \\
\text { personnel and outcome assessors was prob- } \\
\text { ably done }\end{array}$ \\
\hline
\end{tabular}

Incomplete outcome data (attrition bias) Low risk All outcomes
Attrition among neonates was $1.04 \%$ reasons for which were not provided. All analyses performed on an intention-to-treat basis, that is, by randomised treatment group irrespective of individual compliance to the dosing regimen

Comment: published reports included all expected outcomes. 
West 1995 (Continued)

\begin{tabular}{|c|c|c|}
\hline Other bias & Unclear risk & $\begin{array}{l}\text { Supported by a grant from John Hopkins } \\
\text { University and assistance from Hoffmann- } \\
\text { LaRoche industry (Basel, Switzerland). A } \\
\text { protocol is described but no details are pro- } \\
\text { vided }\end{array}$ \\
\hline
\end{tabular}

Characteristics of excluded studies [ordered by study ID]

\begin{tabular}{ll}
\hline Study & Reason for exclusion \\
\hline Bezzera 2009 & $\begin{array}{l}\text { This study included supplementation of mothers only with vitamin A supplements in the immediate postpartum } \\
\text { period and there was no supplementation of neonates with vitamin A }\end{array}$ \\
\hline Bhaskaram 1998 & $\begin{array}{l}\text { This study included supplementation of mothers only with vitamin A supplements within } 24 \text { hours of delivery } \\
\text { while all neonates were given oral poliovirus vaccine (OPV) between } 48 \text { and } 72 \text { hours after birth }\end{array}$ \\
\hline
\end{tabular}

\section{Characteristics of ongoing studies [ordered by study ID]}

Ghana 2010

Trial name or title Efficacy of newborn vitamin A supplementation in improving child survival in rural Ghana: generation of evidence necessary for informing global policy (Neovita)

Methods Double blind, randomised, placebo controlled trial in 7 contiguous districts (Kintampo North, Kintampo South, Wenchi, Tain, Techiman, Nkoranza North and Nkoranza South) in the Brong Ahafo region of central rural Ghana

Participants Inclusion criteria is all births in the study area that are contacted by the study team on the day of birth or in the next 2 days. Both singleton and multiple births are eligible for inclusion in this study and each infant will be provided with their own unique study identification number. Infants will be included even if they were not identified during pregnancy surveillance

Exclusion criteria is if the neonate is unable to feed on offering feeds, as reported by the mother or the mother does not intend to stay in the study area for at least 6 months

Interventions Intervention includes vitamin A 50,000 International Units (IU) once orally within the first 3 days of life keeping a minimum period of 2 hours between the birth and the dosing Placebo capsule of soy bean oil once orally within the first 3 days of life

Outcomes

All cause early infant mortality (0-5 months) assessed at 6 months of age, all cause neonatal mortality (01 month) assessed at 1 month, incidence of severe morbidity defined as hospitalisations due to any illness in the first 6 months of infancy, potential adverse effects of vitamin A such as bulging fontanelle, vomiting, irritability, fever, diarrhoea, inability to suck or feed, convulsions or any other condition that caused parents to be concerned, in the 3 days period following administration of the supplement, and vitamin A and C reactive protein (CRP) status of a subsample of infants at 2 weeks and 3 months of age 
Ghana 2010 (Continued)

\begin{tabular}{ll}
\hline Starting date & Anticipated date of first participant enrolment: Aug 16, 2010 \\
\hline Contact information & $\begin{array}{l}\text { Karen Edmond } \\
\text { London School of Hygiene and Tropical Medicine, Keppel St London, WC1E7HT, UK } \\
\text { Email: karen.edmond@lshtm.ac.uk }\end{array}$ \\
\hline Notes & Target sample size: 28000 \\
\hline
\end{tabular}

India 2010

Trial name or title Efficacy of Neonatal Vitamin A Supplementation in Improving Child Survival in Haryana, India: Generation of Evidence Necessary for Informing Global Policy (NeoVitA Trial)

\begin{tabular}{ll}
\hline Methods & Double blind, randomised, placebo controlled trial in two districts in the state of Haryana, India \\
\hline Participants & $\begin{array}{l}\text { Inclusion criteria is all births in the study area that are contacted by the enrolment team within the eligible } \\
\text { age window (up to } 60 \text { hours of birth) and parent's consent to participate } \\
\text { Exclusion criteria is neonate unable to feed on offering feeds, as reported by the mother or mother does not } \\
\text { intend to stay in the study area for at least } 6 \text { months }\end{array}$ \\
\hline Interventions & $\begin{array}{l}\text { Intervention includes retinol palmitate (50,000 IU) and minute amounts of vitamin E in soybean oil, orally } \\
\text { as a single dose to neonates on the day of birth or in the next } 2 \text { days of birth keeping a minimum period of } 2 \\
\text { hours between the birth and the dosing } \\
\text { Placebo capsules will contain minute amounts of vitamin E in soybean oil }\end{array}$ \\
\hline
\end{tabular}

Outcomes Infant mortality at 6 months, mortality in the neonatal period (first month of life), incidence of severe morbidity defined as hospitalizations due to any illness in the first 6 months of infancy; bulging fontanelle, vomiting, irritability, fever, diarrhea, inability to suck or feed, convulsions or any other conditions that caused parents to be concerned, in the 3 day period following administration of the supplement; and vitamin A status in a subgroup of newborns and caregivers

\begin{tabular}{ll} 
Starting date & June 2010 \\
\hline Contact information & $\begin{array}{l}\text { Nita Bhandari } \\
\text { Society for Applied Studies }\end{array}$ \\
& New Delhi, Delhi, India, 110016 \\
& $00911146043751-55$ ext 201 \\
& Email: CHRD@sas.org.in
\end{tabular}

Notes $\quad$ Estimated enrolment: 40200

Estimated study completion date: November 2013

Neonatal vitamin A supplementation for the prevention of mortality and morbidity in term neonates in developing countries (Review) 
Trial name or title Feasibility study of delivering a neonatal dose of vitamin A through the Lady Health Workers (LHWs) program in Pakistan

\begin{tabular}{|c|c|}
\hline Methods & Cluster randomised, double blind, placebo controlled trial in Sukkhur and Jehlum districts in Pakistan \\
\hline Participants & $\begin{array}{l}\text { Inclusion criteria is live born infants from all pregnancies within participating villages } \\
\text { Exclusion criteria is a child born with congenital malformation, serious birth injury, birth asphyxia, serious } \\
\text { infections, gestational age less than } 32 \text { weeks, birthweight less than } 1500 \text { gms and refuse to participate }\end{array}$ \\
\hline Interventions & $\begin{array}{l}\text { Intervention includes routine postpartum care and vitamin A supplementation (50,000 IU) to the newborn } \\
\text { within } 48-72 \text { hours of birth } \\
\text { Control group receives routine postpartum care and placebo. }\end{array}$ \\
\hline Outcomes & $\begin{array}{l}\text { All cause infant mortality at } 6 \text { months, cause-specific infant mortality at } 6 \text { months of age, serum retinol values, } \\
\text { rates of breastfeeding and incidence of serious infections (sepsis, pneumonia and diarrhoea) }\end{array}$ \\
\hline Starting date & January 2007 \\
\hline Contact information & $\begin{array}{l}\text { Zulfiqar A Bhutta } \\
\text { Division of Women \& Child Health } \\
\text { The Aga Khan University, Karachi 74800, Pakistan } \\
\text { Email : zulfiqar.bhutta@aku.edu }\end{array}$ \\
\hline Notes & $\begin{array}{l}\text { Estimated enrolment: } 7400 \\
\text { Expected completion date: April } 2010\end{array}$ \\
\hline
\end{tabular}

Tanzania 2010

\begin{tabular}{ll} 
Trial name or title & $\begin{array}{l}\text { Efficacy of newborn vitamin A supplementation in improving child survival in Tanzania: generation of } \\
\text { evidence necessary for informing global policy }\end{array}$ \\
\hline Methods & $\begin{array}{l}\text { Double blind, randomised, placebo controlled trial in Dar-es-Salaam, and Kilombero and Ulanga districts in } \\
\text { Ifakara, Tanzania }\end{array}$ \\
\hline Participants & $\begin{array}{l}\text { Inclusion criteria is all births in the study area that are between two hours and two days of age, whose caretakers } \\
\text { confirm of intention to remain in the study areas for a minimum of six months thereafter. Both singleton } \\
\text { and multiple births are eligible for inclusion in this study and each infant will be provided with their own } \\
\text { unique study identification number. Infants will be included even if they were not identified during pregnancy } \\
\text { surveillance } \\
\text { Exclusion criteria is if the neonate is unable to feed on offering feeds, the mother does not intend to stay in } \\
\text { the study area for at least } 6 \text { months and women younger than } 18 \text { years old }\end{array}$ \\
\hline
\end{tabular}

Interventions Intervention includes vitamin A 50,000 International Units (IU) as retinol palmitate and minute amounts of vitamin $\mathrm{E}$ in soybean oil, once orally within the first 3 days of life keeping a minimum period of 2 hours between the birth and the dosing

Placebo capsule with minute amounts of vitamin $\mathrm{E}$ in soybean oil once orally within the first 3 days of life

Neonatal vitamin A supplementation for the prevention of mortality and morbidity in term neonates in developing countries (Review) 
Tanzania 2010 (Continued)

\begin{tabular}{ll} 
Outcomes & $\begin{array}{l}\text { Infant mortality assessed at } 6 \text { months of age, neonatal mortality (0-1 month) assessed at } 1 \text { month, incidence } \\
\text { of severe morbidity defined as hospitalizations due to any illness in the first } 6 \text { months of infancy, potential } \\
\text { adverse effects of vitamin A such as bulging fontanelle, vomiting, irritability, fever, diarrhoea, inability to suck } \\
\text { or feed, convulsions or any other condition that caused parents to be concerned, in the } 3 \text { days period following } \\
\text { administration of the supplement, and vitamin A and C reactive protein (CRP) status of a subsample of } \\
\text { infants at } 2 \text { weeks and } 3 \text { months of age }\end{array}$ \\
\hline Starting date & Anticipated date of first participant enrolment: July 1, 2010 \\
\hline Contact information & $\begin{array}{l}\text { Honorati Masanja } \\
\text { Ifakara Health Institute, PO Box 78373, Dar-es-Salaam, } \\
\text { Tanzania } \\
\text { Email: hmasanja@ihi.or.tz }\end{array}$ \\
\hline Notes & \begin{tabular}{l} 
Target sample size: 32,000 \\
\hline
\end{tabular}
\end{tabular}


DATA ANDANALYSES

Comparison 1. Neonatal vitamin A supplementation versus control

\begin{tabular}{|c|c|c|c|c|}
\hline Outcome or subgroup title & $\begin{array}{l}\text { No. of } \\
\text { studies }\end{array}$ & $\begin{array}{c}\text { No. of } \\
\text { participants }\end{array}$ & Statistical method & Effect size \\
\hline $\begin{array}{l}1 \text { All-cause infant mortality at } 6 \\
\text { months: risk ratios based on } \\
\text { cumulative risk (\%, adjusted } \\
\text { for clustering) }\end{array}$ & 5 & & Risk Ratio (Fixed, 95\% CI) & Subtotals only \\
\hline 1.1 Term infants & 3 & 22721 & Risk Ratio (Fixed, 95\% CI) & $0.82[0.68,0.99]$ \\
\hline 1.2 All infants & 5 & 39040 & Risk Ratio (Fixed, 95\% CI) & $0.86[0.77,0.97]$ \\
\hline $\begin{array}{l}2 \text { All-cause infant mortality at } 6 \\
\text { months: rate ratios (per years of } \\
\text { follow-up) }\end{array}$ & 4 & & Rate Ratio (Fixed, 95\% CI) & Subtotals only \\
\hline 2.1 Term infants & 2 & & Rate Ratio (Fixed, 95\% CI) & $0.91[0.73,1.13]$ \\
\hline 2.2 All infants & 4 & & Rate Ratio (Fixed, 95\% CI) & $0.91[0.77,1.06]$ \\
\hline $\begin{array}{l}3 \text { All-cause infant mortality at } 12 \\
\text { months (all infants): risk ratios } \\
\text { based on cumulative risk (\%) }\end{array}$ & 4 & 15731 & Risk Ratio (M-H, Fixed, 95\% CI) & $1.02[0.87,1.20]$ \\
\hline $\begin{array}{l}4 \text { All-cause infant mortality at } 12 \\
\text { months: rate ratios (per years of } \\
\text { follow-up) }\end{array}$ & 4 & & Rate Ratio (Fixed, 95\% CI) & Subtotals only \\
\hline 4.1 Term infants & 2 & & Rate Ratio (Fixed, 95\% CI) & $0.95[0.72,1.26]$ \\
\hline 4.2 All infants & 4 & & Rate Ratio (Fixed, 95\% CI) & $1.03[0.87,1.23]$ \\
\hline $\begin{array}{l}5 \text { Cause-specific infant mortality at } \\
6 \text { months (all infants): Diarrhea }\end{array}$ & 2 & & (Fixed, 95\% CI) & Totals not selected \\
\hline 5.1 Risk ratio & 1 & & (Fixed, 95\% CI) & $0.0[0.0,0.0]$ \\
\hline 5.2 Rate ratio & 1 & & (Fixed, 95\% CI) & $0.0[0.0,0.0]$ \\
\hline $\begin{array}{l}6 \text { Cause-specific infant mortality } \\
\text { at } 6 \text { months (all infants): } \\
\text { Respiratory infections }\end{array}$ & 2 & & (Fixed, 95\% CI) & Totals not selected \\
\hline 6.1 Risk ratio & 1 & & (Fixed, 95\% CI) & $0.0[0.0,0.0]$ \\
\hline 6.2 Rate ratio & 1 & & (Fixed, 95\% CI) & $0.0[0.0,0.0]$ \\
\hline $\begin{array}{l}7 \text { Cause-specific infant mortality } \\
\text { at } 12 \text { months (all infants): } \\
\text { Diarrhoea }\end{array}$ & 3 & & (Fixed, 95\% CI) & Subtotals only \\
\hline 7.1 Risk ratios & 1 & & (Fixed, 95\% CI) & $0.40[0.08,2.03]$ \\
\hline 7.2 Rate ratios & 2 & & (Fixed, 95\% CI) & $1.32[0.80,2.16]$ \\
\hline $\begin{array}{l}8 \text { Cause-speciifc infant mortality } \\
\text { at } 12 \text { months (all infants): } \\
\text { Respiratory infections }\end{array}$ & 3 & & (Fixed, 95\% CI) & Subtotals only \\
\hline 8.1 Risk ratios & 1 & & (Fixed, 95\% CI) & $0.66[0.11,3.95]$ \\
\hline 8.2 Rate ratios & 2 & & (Fixed, 95\% CI) & $0.97[0.67,1.42]$ \\
\hline $\begin{array}{l}9 \text { Infant morbidity at } 6 \text { months } \\
\text { (rate ratio): Diarrhoea }\end{array}$ & 2 & & Rate ratio (Fixed, 95\% CI) & $1.05[0.99,1.10]$ \\
\hline $\begin{array}{l}10 \text { Infant morbidity at } 6 \text { months } \\
\text { (rate ratio): Respiratory } \\
\text { infections }\end{array}$ & 2 & & Rate ratio (Fixed, 95\% CI) & $1.01[0.96,1.05]$ \\
\hline
\end{tabular}

Neonatal vitamin A supplementation for the prevention of mortality and morbidity in term neonates in developing countries (Review) 36

Copyright @ 2012 The Cochrane Collaboration. Published by John Wiley \& Sons, Ltd. 
11 Vitamin A deficient (serum retinol $<0.70 \mathrm{micromol} / \mathrm{L}$ ) at 6 weeks of age

12 Vitamin A deficient (serum retinol $<0.70 \mathrm{micromol} / \mathrm{L}$ ) at 4 months of age

13 Anaemia (haemoglobin $<105 \mathrm{~g} / \mathrm{L}$ ) at $8-14$ months of age

14 Adverse events during the first 48-72 hours post supplementation

14.1 Bulging fontanelle
14.2 Diarrhoea
14.3 Vomiting
Adverse events during the first
month post supplementation
15.1 Diarrhoea
15.2 Vomiting

Totals not selected

Subtotals only
$0.92[0.77,1.09]$

$0.88[0.74,1.05]$

Totals not selected

$0.0[0.0,0.0]$ $0.0[0.0,0.0]$

Analysis I.I. Comparison I Neonatal vitamin A supplementation versus control, Outcome I All-cause infant mortality at 6 months: risk ratios based on cumulative risk (\%, adjusted for clustering).

Review: Neonatal vitamin A supplementation for the prevention of mortality and morbidity in term neonates in developing countries

Comparison: I Neonatal vitamin A supplementation versus control

Outcome: I All-cause infant mortality at 6 months: risk ratios based on cumulative risk (\%, adjusted for clustering)

\begin{tabular}{|c|c|c|c|c|c|c|c|c|}
\hline \multirow[t]{2}{*}{ Study or subgroup } & \multirow{2}{*}{$\begin{array}{r}\text { Favours vitamin A } \\
N\end{array}$} & \multirow{2}{*}{$\begin{array}{r}\text { Control } \\
\mathrm{N}\end{array}$} & \multirow{2}{*}{$\begin{array}{r}\log \text { [Risk Ratio] } \\
\text { (SE) }\end{array}$} & \multirow{2}{*}{\multicolumn{3}{|c|}{ Risk Ratio }} & \multirow[t]{2}{*}{ Weight } & \multirow{2}{*}{$\begin{array}{r}\text { Risk Ratio } \\
\text { IV,Fixed,95\% Cl }\end{array}$} \\
\hline & & & & & & & & \\
\hline \multicolumn{9}{|l|}{ I Term infants } \\
\hline Humphrey 1996 & 1011 & 1007 & $-0.9163(0.4776)$ & & & & $4.2 \%$ & $0.40[0.16,1.02]$ \\
\hline Klemm 2008 & 6109 & 6061 & $-0.2877(0.1206)$ & & & & $65.5 \%$ & $0.75[0.59,0.95]$ \\
\hline Malaba 2005 & 4253 & 4280 & $0.0862(0.1773)$ & & & 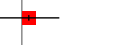 & $30.3 \%$ & $1.09[0.77,1.54]$ \\
\hline Subtotal (95\% CI) & 11373 & 11348 & & & & - & $100.0 \%$ & $0.82[0.68,0.99]$ \\
\hline \multicolumn{9}{|c|}{ Heterogeneity: $\mathrm{Chi}^{2}=5.38, \mathrm{df}=2(P=0.07) ; \mathrm{I}^{2}=63 \%$} \\
\hline \multicolumn{9}{|c|}{ Test for overall effect: $Z=2.06(P=0.040)$} \\
\hline \multicolumn{9}{|l|}{2 All infants } \\
\hline Humphrey 1996 & 1034 & 1033 & $-0.9416(0.4861)$ & & & & $1.6 \%$ & $0.39[0.15,1.01]$ \\
\hline Klemm 2008 & 7953 & 7984 & $-0.1586(0.0845)$ & & & 7 & $52.1 \%$ & $0.85[0.72,1.01]$ \\
\hline \multirow[t]{3}{*}{ Malaba 2005} & 4309 & 4352 & $0.1133(0.1717)$ & & & \pm & $12.6 \%$ & $1.12[0.80,1.57]$ \\
\hline & & & & 0.2 & 0.5 & 2 & 5 & \\
\hline & & & & Favours & $\operatorname{amin} A$ & Favours & ntrol & \\
\hline
\end{tabular}

Neonatal vitamin A supplementation for the prevention of mortality and morbidity in term neonates in developing countries (Review) 


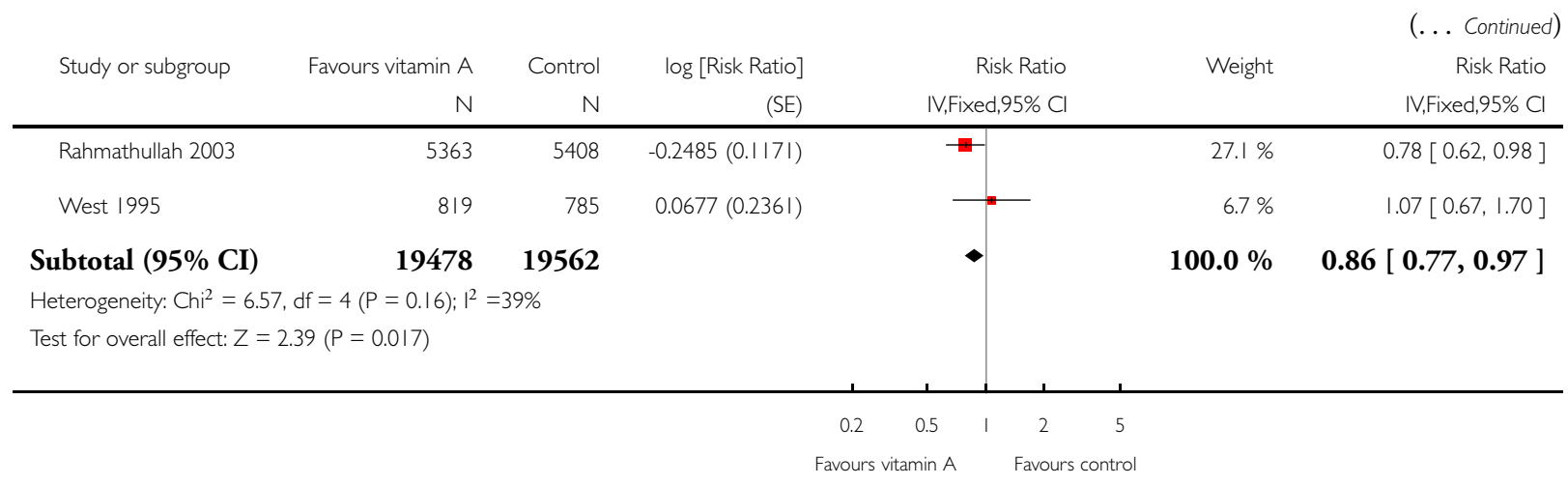

Analysis I.2. Comparison I Neonatal vitamin A supplementation versus control, Outcome 2 All-cause infant mortality at 6 months: rate ratios (per years of follow-up).

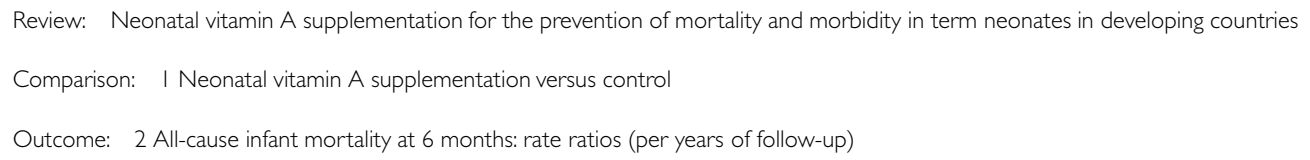

Subtotal (95\% CI)

Heterogeneity: $\mathrm{Chi}^{2}=2.06, \mathrm{df}=|(P=0.15) ;|^{2}=51 \%$

Test for overall effect: $Z=0.87(P=0.39)$

2 All infants

$\begin{array}{lr}\text { Benn } 2008 & 0.13102826(0.19420535) \\ \text { Benn } 2010 & 0.0099(0.1796) \\ \text { Rahmathullah 2003 } & -0.25059(0.110311) \\ \text { West 1995 } & 0.067434(0.236067)\end{array}$

Subtotal (95\% CI)

Heterogeneity: $\mathrm{Chi}^{2}=4.16, \mathrm{df}=3(P=0.25) ;\left.\right|^{2}=28 \%$

Test for overall effect: $Z=1.24(P=0.21)$

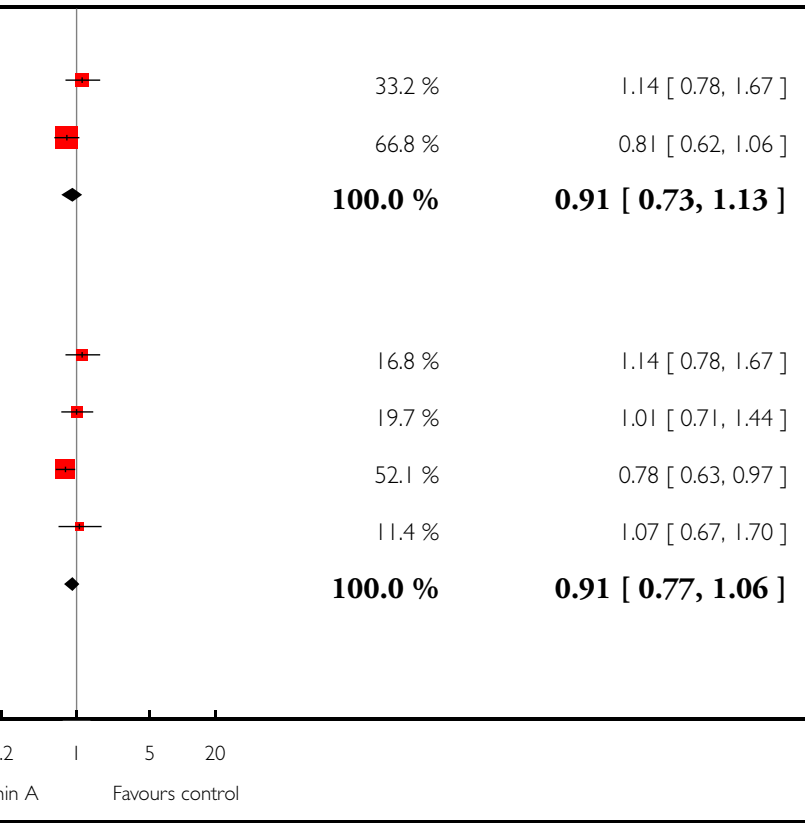

Neonatal vitamin A supplementation for the prevention of mortality and morbidity in term neonates in developing countries (Review) 
Analysis I.3. Comparison I Neonatal vitamin A supplementation versus control, Outcome 3 All-cause infant mortality at 12 months (all infants): risk ratios based on cumulative risk (\%).

Review: Neonatal vitamin A supplementation for the prevention of mortality and morbidity in term neonates in developing countries

Comparison: I Neonatal vitamin A supplementation versus control

Outcome: 3 All-cause infant mortality at 12 months (all infants): risk ratios based on cumulative risk (\%)

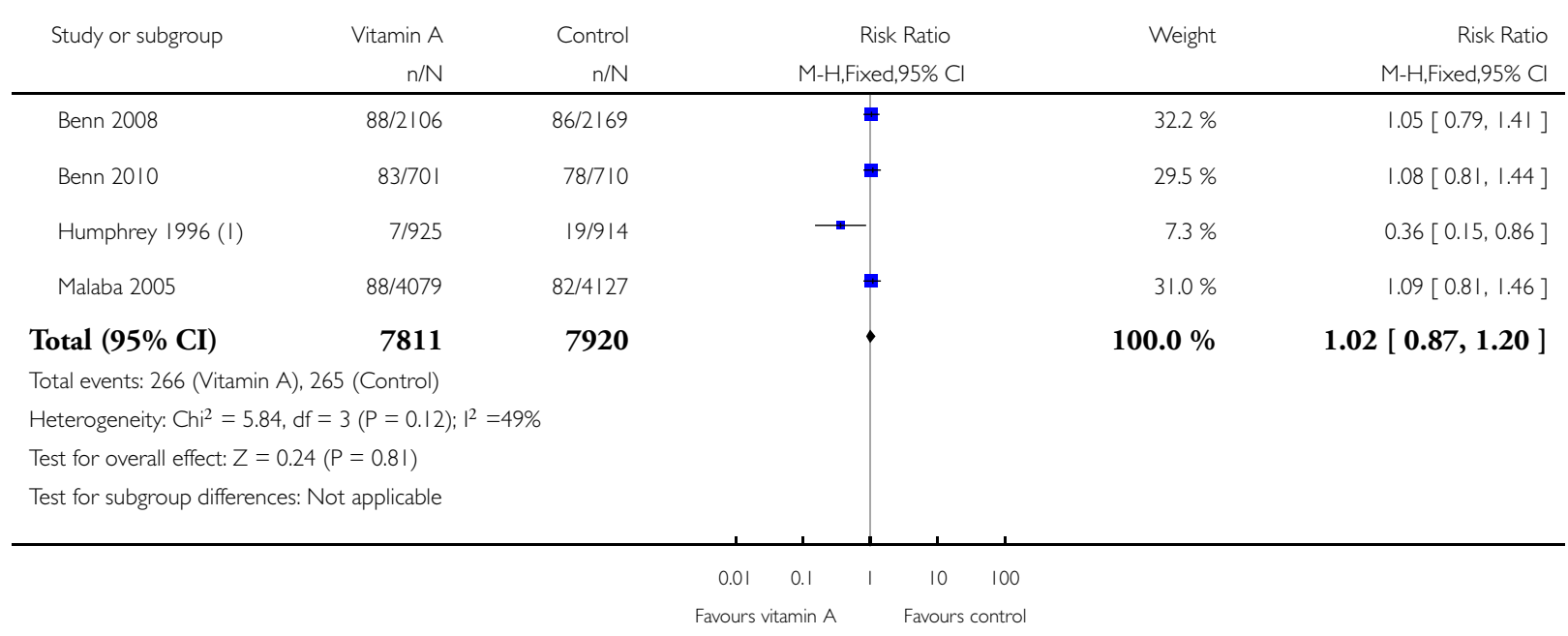

( I) Contains $6 \%$ preterms

Neonatal vitamin A supplementation for the prevention of mortality and morbidity in term neonates in developing countries (Review) 
Analysis I.4. Comparison I Neonatal vitamin A supplementation versus control, Outcome 4 All-cause infant mortality at 12 months: rate ratios (per years of follow-up).

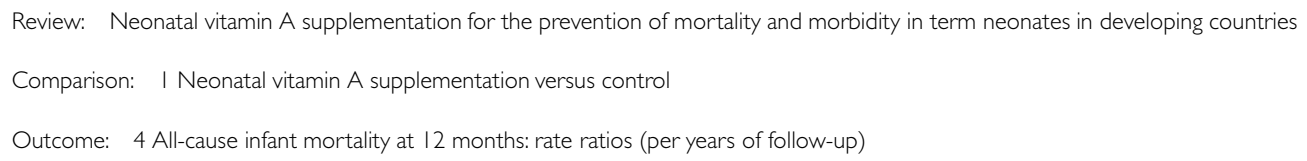

$\begin{array}{ll}\text { | Term infants } & \\ \text { Benn } 2008 & 0.0677(0.1516) \\ \text { Humphrey 1996(I) } & -1.0216(0.4421)\end{array}$

Subtotal $(95 \%$ CI)

Heterogeneity: $\mathrm{Chi}^{2}=5.43, \mathrm{df}=\mathrm{I}(\mathrm{P}=0.02) ; \mathrm{I}^{2}=82 \%$

Test for overall effect: $Z=0.33(P=0.74)$

2 All infants

$\begin{array}{lr}\text { Benn } 2008 & 0.0709(0.1516) \\ \text { Benn } 2010 & 0.0769(0.1584) \\ \text { Humphrey 1996 } & -1.0216(0.4421) \\ \text { Malaba } 2005 & 0.0811(0.153489)\end{array}$

Subtotal (95\% CI)

Heterogeneity: $\mathrm{Chi}^{2}=5.93, \mathrm{df}=3(\mathrm{P}=0.12) ; \mathrm{I}^{2}=49 \%$

Test for overall effect: $Z=0.38(P=0.70)$

IV,Fixed,95\% Cl

-

(I) Contains $6 \%$ preterms 
Analysis I.5. Comparison I Neonatal vitamin A supplementation versus control, Outcome 5 Cause-specific infant mortality at 6 months (all infants): Diarrhea.

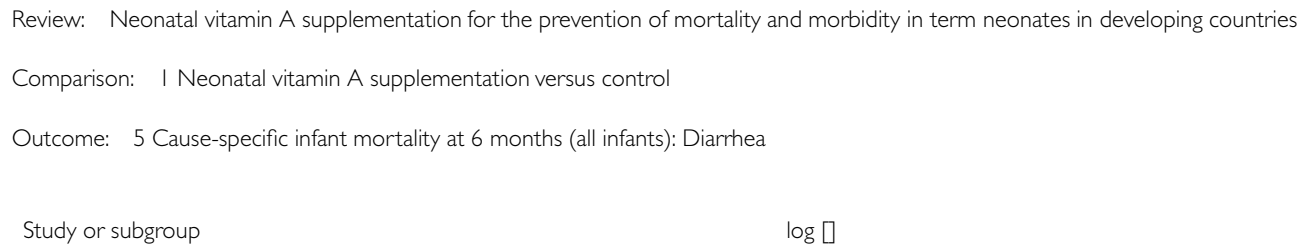

|rix

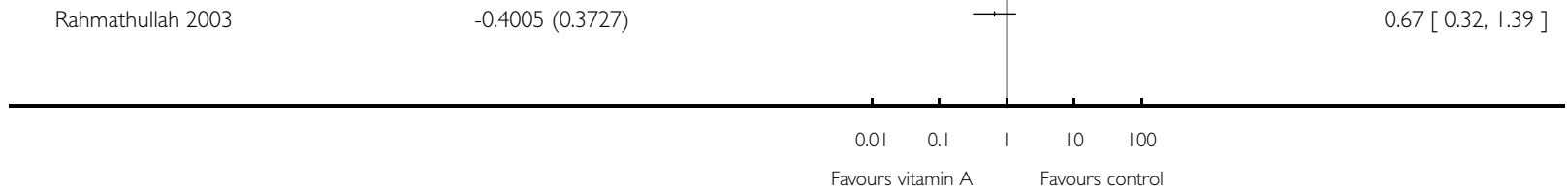

Analysis 1.6. Comparison I Neonatal vitamin A supplementation versus control, Outcome 6 Cause-specific infant mortality at 6 months (all infants): Respiratory infections.

Review: Neonatal vitamin A supplementation for the prevention of mortality and morbidity in term neonates in developing countries

Comparison: I Neonatal vitamin A supplementation versus control

Outcome: 6 Cause-specific infant mortality at 6 months (all infants): Respiratory infections

Study or subgroup

\section{Risk ratio}

Humphrey 1996

2 Rate ratio

Rahmathullah 2003
(SE)

-0.4155 (0.9076)

$0.0019(0.2949)$ $\log []$

IV,Fixed,95\% Cl

IV,Fixed,95\% Cl

$0.66[0.11,3.91]$

$1.00[0.56,1.79]$ 
Analysis I.7. Comparison I Neonatal vitamin A supplementation versus control, Outcome 7 Cause-specific infant mortality at 12 months (all infants): Diarrhoea.

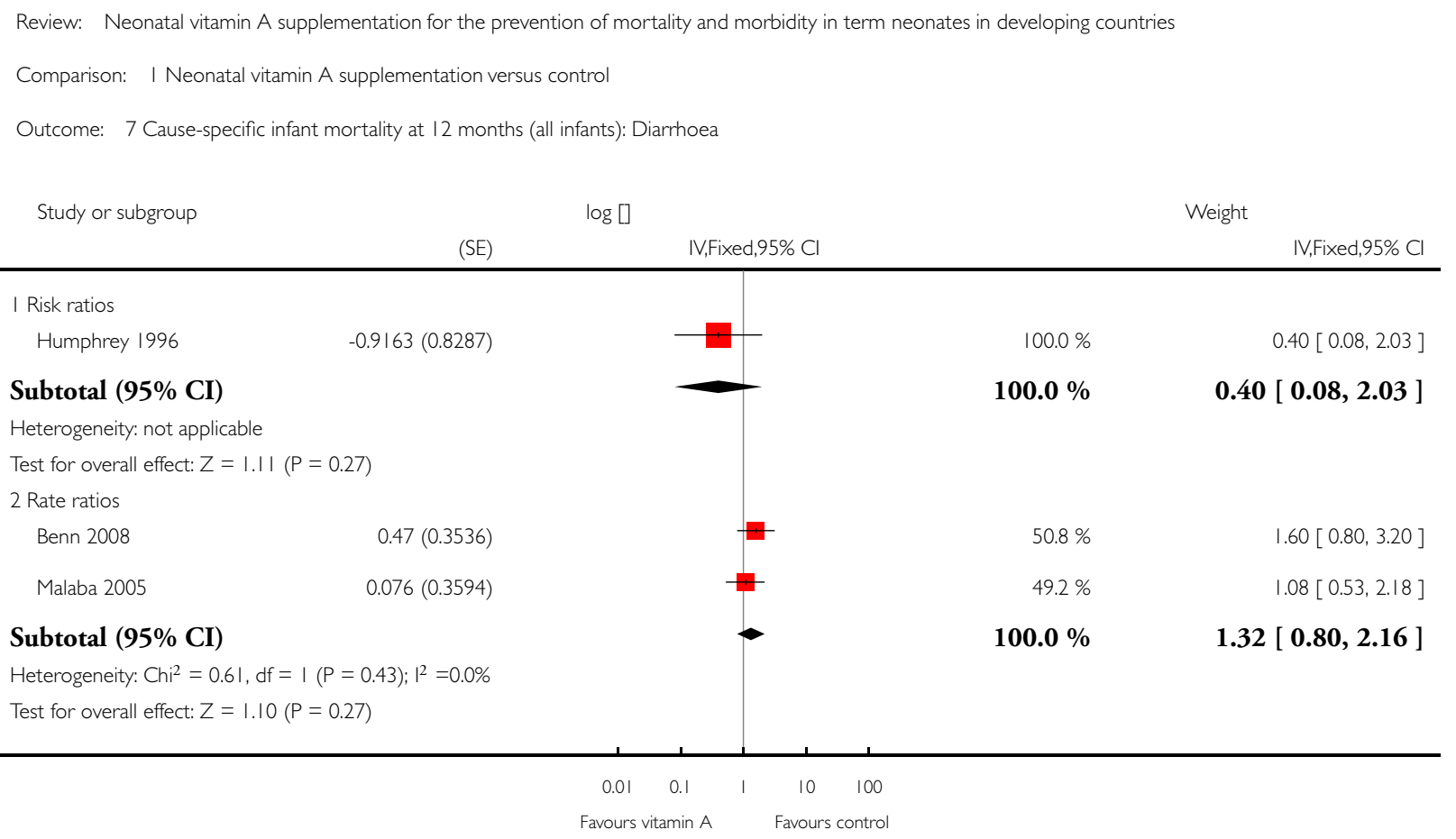


Analysis I.8. Comparison I Neonatal vitamin A supplementation versus control, Outcome 8 Cause-speciifc infant mortality at 12 months (all infants): Respiratory infections.

Review: Neonatal vitamin A supplementation for the prevention of mortality and morbidity in term neonates in developing countries

Comparison: I Neonatal vitamin A supplementation versus control

Outcome: 8 Cause-speciifc infant mortality at 12 months (all infants): Respiratory infections

Study or subgroup $\quad \log [] \quad$ Weight

(SE) IV,Fixed,95\% Cl IV,Fixed,95\% Cl

I Risk ratios

Humphrey $1996 \quad-0.4155(0.9128)$

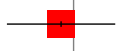

$100.0 \%$

$0.66[0.11,3.95]$

Subtotal (95\% CI)

Heterogeneity: not applicable

Test for overall effect: $Z=0.46(P=0.65)$

2 Rate ratios

$\begin{array}{ll}\text { Benn } 2008 & 0.0953(0.4188) \\ \text { Malaba } 2005 & -0.0596(0.2171)\end{array}$

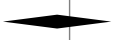

$100.0 \%$

$0.66[0.11,3.95$ ]

Subtotal (95\% CI)

Heterogeneity: $\mathrm{Chi}^{2}=0.1 \mathrm{I}, \mathrm{df}=\mathrm{I}(\mathrm{P}=0.74) ; \mathrm{I}^{2}=0.0 \%$

Test for overall effect: $Z=0.14(P=0.89)$

$21.2 \%$

$78.8 \%$

$100.0 \%$
I. $10[0.48,2.50]$

$0.94[0.62,1.44]$

$0.97[0.67,1.42]$ 
Analysis I.9. Comparison I Neonatal vitamin A supplementation versus control, Outcome 9 Infant morbidity at 6 months (rate ratio): Diarrhoea.

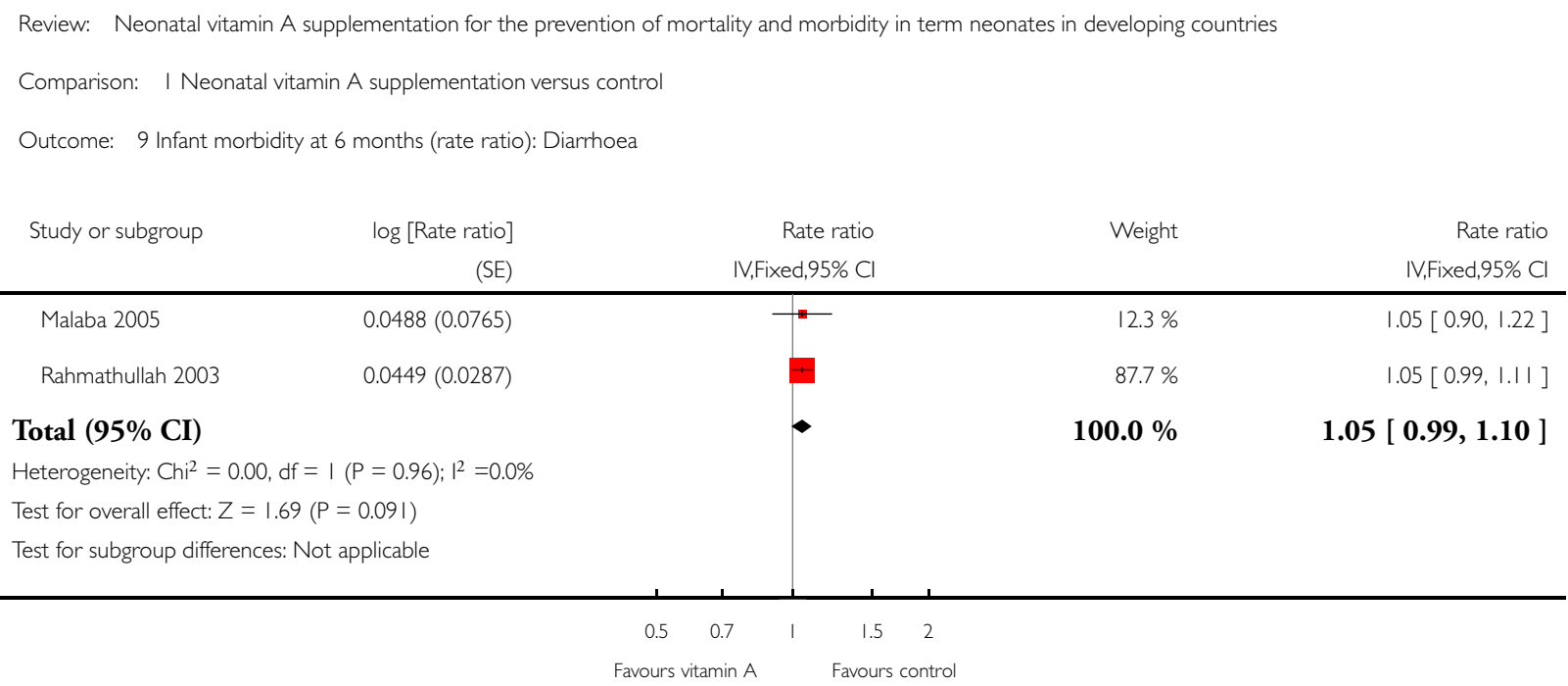

\section{Analysis I.10. Comparison I Neonatal vitamin A supplementation versus control, Outcome I0 Infant} morbidity at 6 months (rate ratio): Respiratory infections.

Review: Neonatal vitamin A supplementation for the prevention of mortality and morbidity in term neonates in developing countries

Comparison: I Neonatal vitamin A supplementation versus control

Outcome: 10 Infant morbidity at 6 months (rate ratio): Respiratory infections

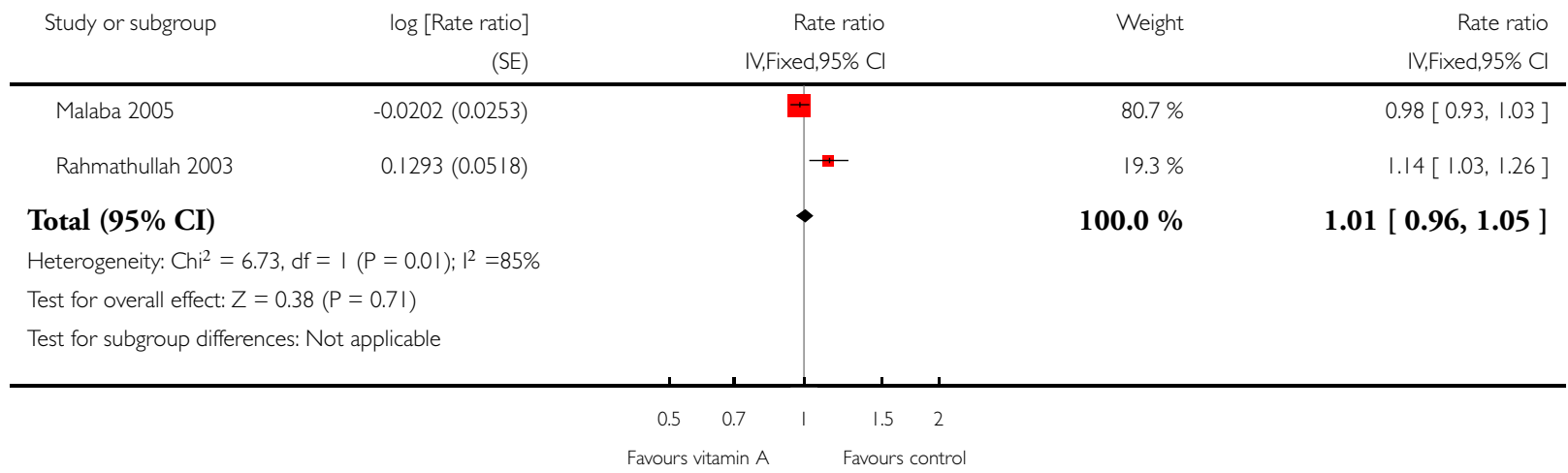

Neonatal vitamin A supplementation for the prevention of mortality and morbidity in term neonates in developing countries (Review) 


\section{Analysis I.I I. Comparison I Neonatal vitamin A supplementation versus control, Outcome I I Vitamin A deficient (serum retinol $<0.70 \mathrm{micromol} / \mathrm{L}$ ) at 6 weeks of age.}

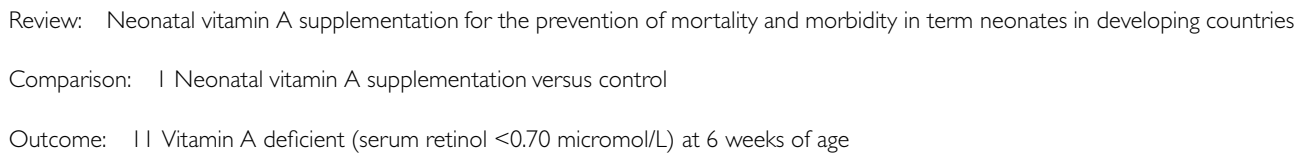

\begin{tabular}{cccc} 
Study or subgroup & $\begin{array}{r}\text { Control } \\
\mathrm{n} / \mathrm{N}\end{array}$ & $\mathrm{n} / \mathrm{N}$ & $\mathrm{M}-\mathrm{H}, \mathrm{Fixed}, 95 \% \mathrm{Cl}$ \\
\hline Benn 2008 & $91 / 292$ & $106 / 320$ & + \\
& & & $\mathrm{M}-\mathrm{H}, \mathrm{Fixed}, 95 \% \mathrm{Cl}$ \\
\hline
\end{tabular}

$\begin{array}{lllll}0.01 & 0.1 & 1 & 10 & 100\end{array}$

Favours vitamin A Favours control

\section{Analysis I.12. Comparison I Neonatal vitamin A supplementation versus control, Outcome I2 Vitamin A deficient (serum retinol $<0.70 \mathrm{micromol} / \mathrm{L}$ ) at 4 months of age.}

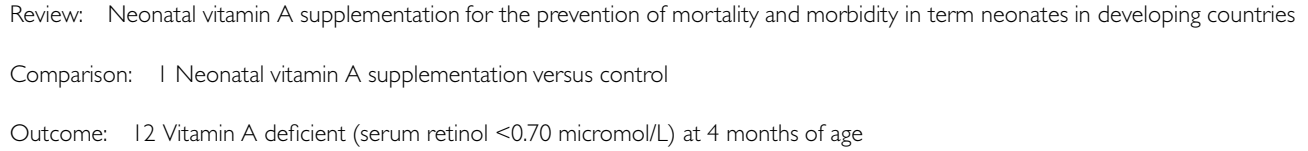

\begin{tabular}{ccccc} 
& $\mathrm{n} / \mathrm{N}$ & $\mathrm{M} / \mathrm{N}$ & $\mathrm{M}, \mathrm{H}, \mathrm{Fixed}, 95 \% \mathrm{Cl}$ & $\mathrm{M}, \mathrm{Fixed}, 95 \% \mathrm{Cl}$ \\
\hline Benn 2008 & $30 / 186$ & $29 / 183$ & $-1.02[0.64,1.62]$
\end{tabular}

\begin{tabular}{ll|l}
$1.02[0.64,1.62]$ & \\
\hline & 1
\end{tabular}

$\begin{array}{lllll}0.01 & 0.1 & 1 & 10 & 100\end{array}$

Favours vitamin A Favours control 
Analysis I.13. Comparison I Neonatal vitamin A supplementation versus control, Outcome I3 Anaemia (haemoglobin $<105 \mathrm{~g} / \mathrm{L}$ ) at 8-14 months of age.

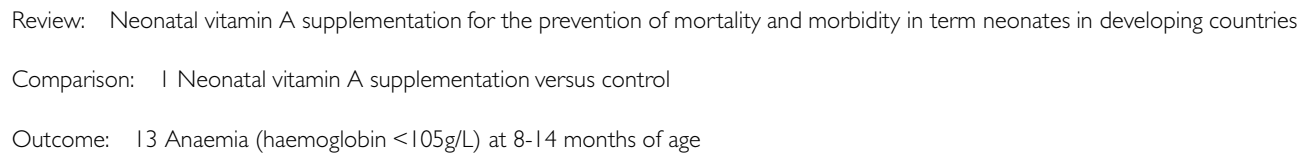

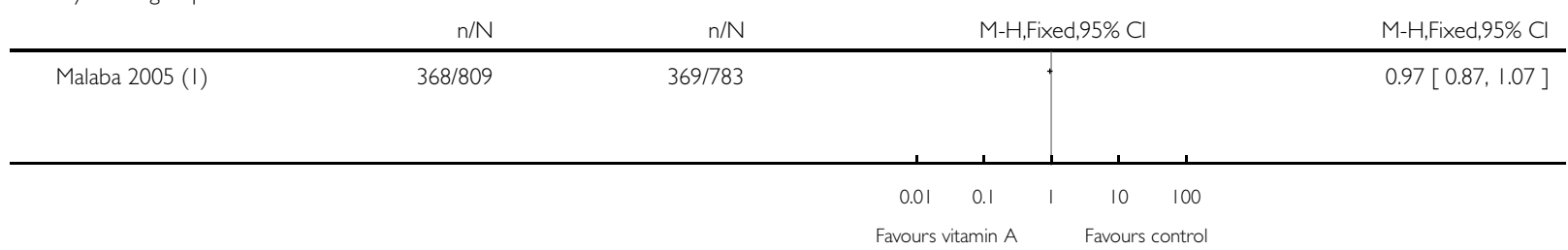

(I) Includes both HIV +/ - mothers but HIV status of the m/i did not modify the association b/w vitamin A supplementation and anaemia

Analysis I.14. Comparison I Neonatal vitamin A supplementation versus control, Outcome I4 Adverse events during the first 48-72 hours post supplementation.

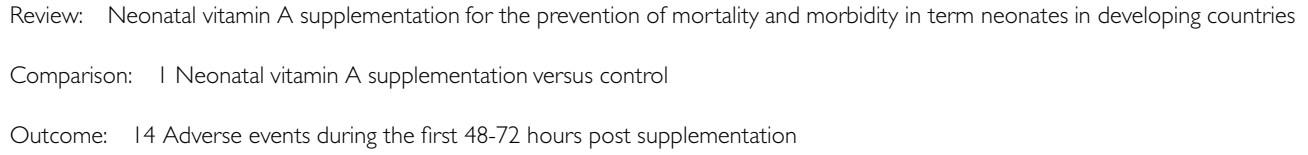

Subtotal (95\% CI)

Total events: I06 (Intervention), 8 I (Control)
Heterogeneity: Chi $^{2}=2.25, \mathrm{df}=$ I $(P=0.13) ;\left.\right|^{2}=56 \%$

Test for overall effect: $Z=2.24(P=0.025)$

2 Diarrhoea

$\begin{array}{lll}\text { Benn } 2008 & 103 / 551 & \text { I46/599 } \\ \text { Humphrey 1996 } & \text { 104/1008 } & \text { 90/100। }\end{array}$

Subtotal (95\% CI)

1559

1600

$31.8 \%$

$1.83[1.13,2.95]$

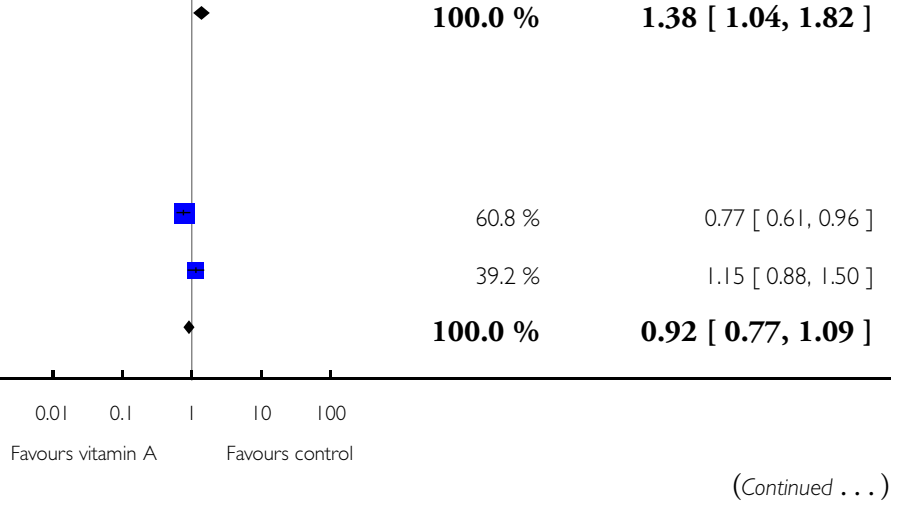




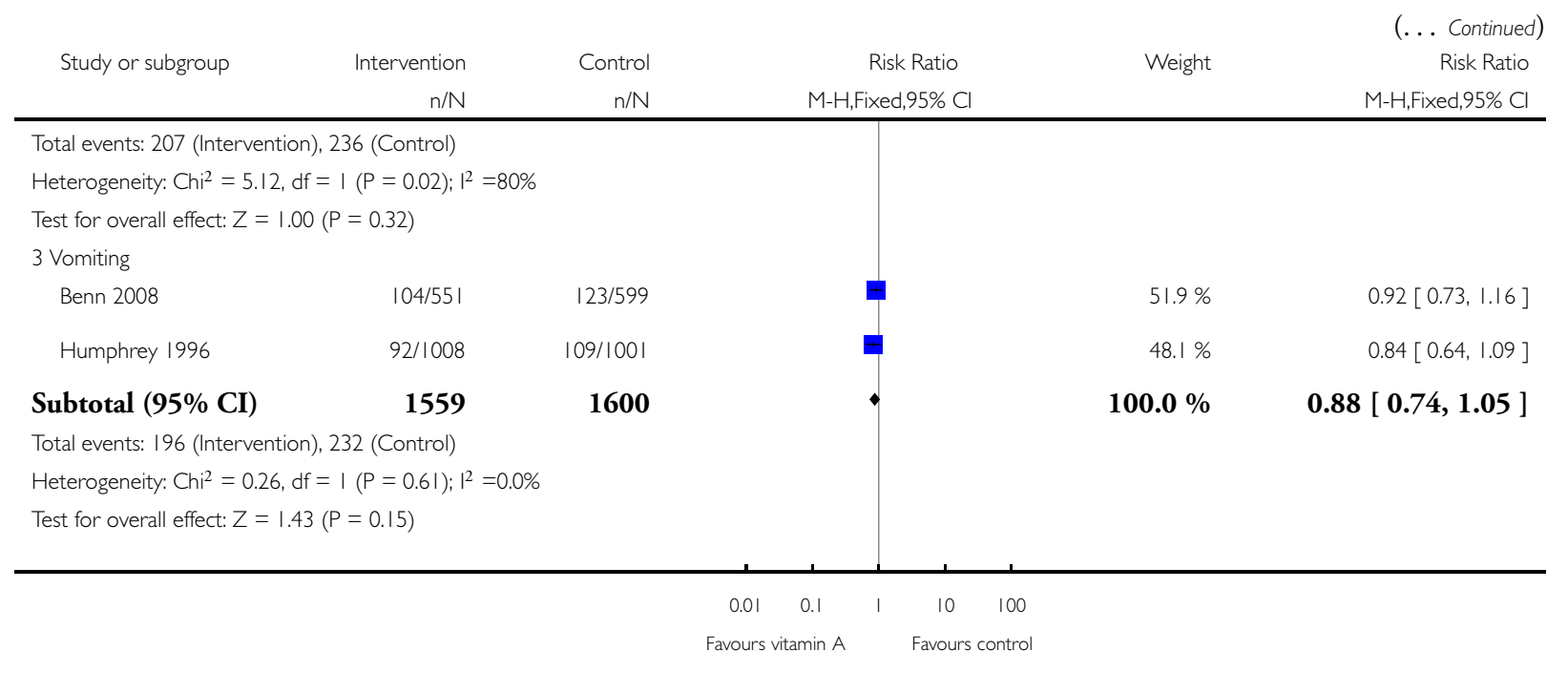

Analysis I.I5. Comparison I Neonatal vitamin A supplementation versus control, Outcome I5 Adverse events during the first month post supplementation.

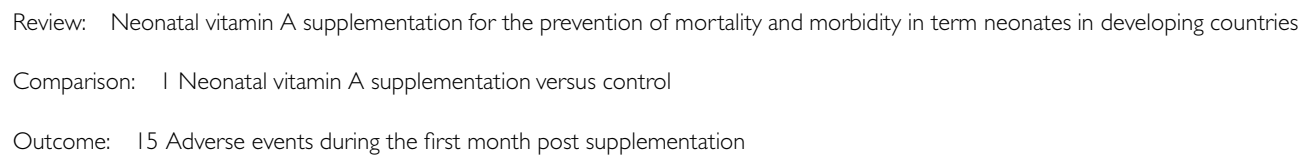

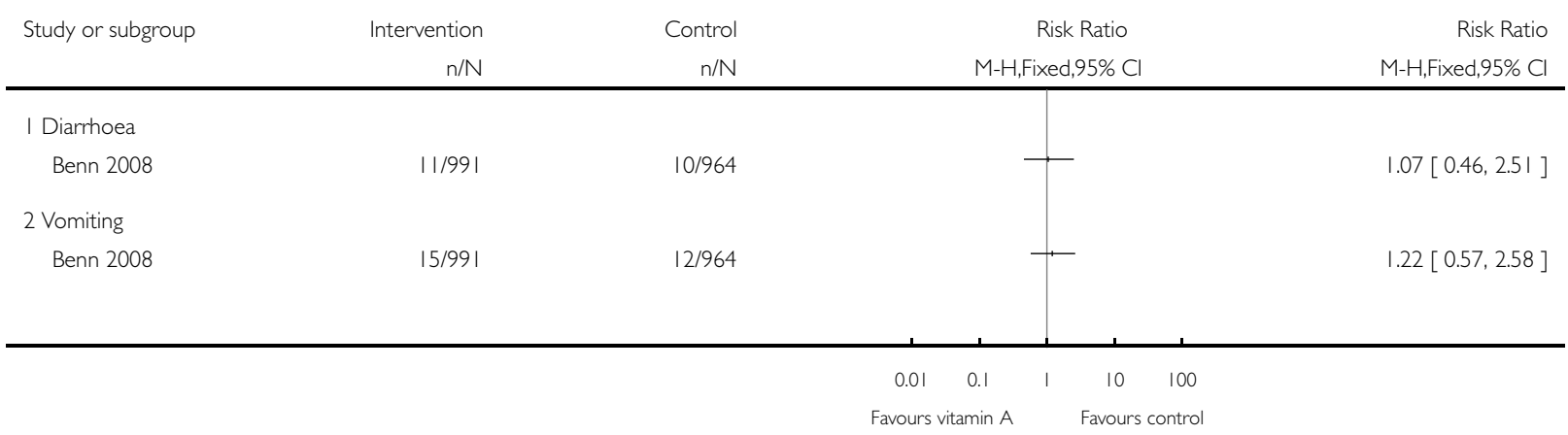


ADDITIONAL TABLES

Table 1. Data type and source: all-cause infant mortality at 6 months

\begin{tabular}{|c|c|c|c|c|c|c|c|c|c|}
\hline Study ID & $\begin{array}{l}\text { Analyzed } \\
\text { as Rate/ } \\
\text { Risk ratio }\end{array}$ & $\begin{array}{l}\text { Data } \\
\text { source } \\
\text { (term/all } \\
\text { infants) }\end{array}$ & Infants & $\begin{array}{l}\text { Vitamin A } \\
\text { group: } \\
\text { Deaths }\end{array}$ & $\begin{array}{l}\text { Vitamin A } \\
\text { group: } \\
\text { Child- } \\
\text { years of } \\
\text { follow-up }\end{array}$ & $\begin{array}{l}\text { Vitamin A } \\
\text { group: } \\
\mathbf{N}\end{array}$ & $\begin{array}{l}\text { Control } \\
\text { group: } \\
\text { Deaths }\end{array}$ & $\begin{array}{l}\text { Control } \\
\text { group: } \\
\text { Child- } \\
\text { years of } \\
\text { follow-up }\end{array}$ & $\begin{array}{l}\text { Control } \\
\text { group: } \\
\mathrm{N}\end{array}$ \\
\hline Benn 2008 & Rate ratio & $\begin{array}{l}\text { Corre- } \\
\text { spon- } \\
\text { dence with } \\
\text { study in- } \\
\text { vestigators }\end{array}$ & All infants & 55 & 964 & - & 50 & 1003 & - \\
\hline Benn 2010 & Rate ratio & $\begin{array}{l}\text { Corre- } \\
\text { spon- } \\
\text { dence with } \\
\text { study in- } \\
\text { vestigators }\end{array}$ & All infants & 62 & 393 & - & 62 & 397 & - \\
\hline \multirow[t]{2}{*}{$\begin{array}{l}\text { Humphrey } \\
1996\end{array}$} & \multirow[t]{2}{*}{ Risk ratio } & \multirow{2}{*}{$\begin{array}{l}\text { Corre- } \\
\text { spondence } \\
\text { with study } \\
\text { investi- } \\
\text { gators (de- } \\
\text { nom- } \\
\text { inators are } \\
\text { number of } \\
\text { neonates } \\
\text { ran- } \\
\text { domised) }\end{array}$} & All infants & 7 & - & 1034 & 18 & - & 1033 \\
\hline & & & $\begin{array}{l}\text { Term } \\
\text { infants }\end{array}$ & 6 & - & 1011 & 15 & - & 1007 \\
\hline \multirow[t]{2}{*}{$\begin{array}{l}\text { Klemm } \\
2008\end{array}$} & \multirow[t]{2}{*}{ Risk ratio } & \multirow{2}{*}{$\begin{array}{l}\text { Klemm } \\
\text { at al, Pedi- } \\
\text { atrics } \\
2008 ; 122 \\
(1): \mathrm{e} 242- \\
50 .\end{array}$} & All infants & 306 & - & 7953 & 360 & - & 7984 \\
\hline & & & $\begin{array}{l}\text { Term } \\
\text { infants }\end{array}$ & 129 & - & 6109 & 171 & - & 6061 \\
\hline $\begin{array}{l}\text { Malaba } \\
2005\end{array}$ & Risk ratio & $\begin{array}{l}\text { Corre- } \\
\text { spondence } \\
\text { with study } \\
\text { investiga- } \\
\text { tors. Data } \\
\text { aggre- } \\
\text { gated for } \\
\text { the four } \\
\text { treatment } \\
\text { groups: } \\
\text { Maternal }\end{array}$ & All infants & 73 & - & 4309 & 66 & - & 4352 \\
\hline
\end{tabular}

Neonatal vitamin A supplementation for the prevention of mortality and morbidity in term neonates in developing countries (Review) 
Table 1. Data type and source: all-cause infant mortality at $\mathbf{6}$ months (Continued)

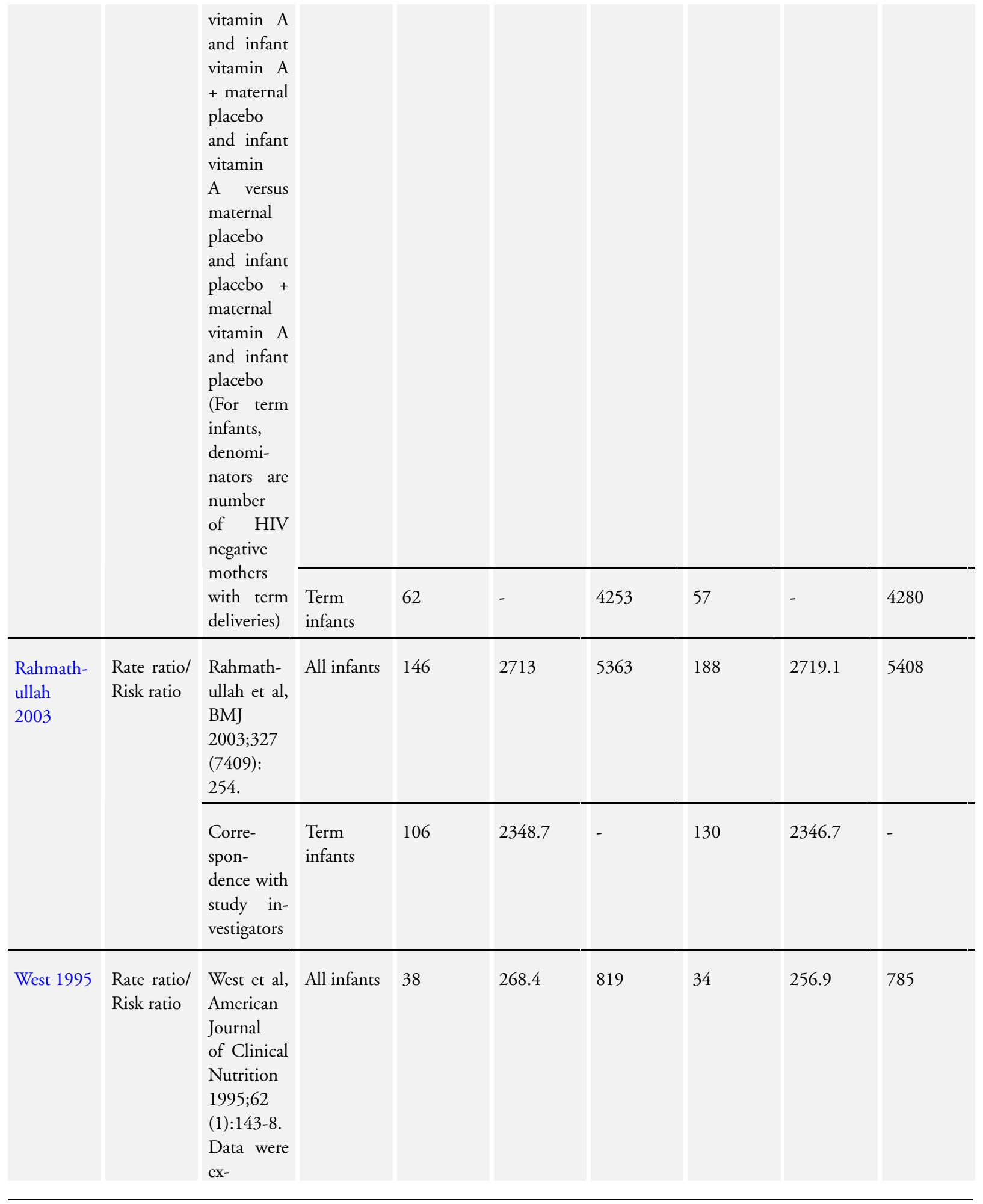

Neonatal vitamin A supplementation for the prevention of mortality and morbidity in term neonates in developing countries (Review) 
Table 1. Data type and source: all-cause infant mortality at $\mathbf{6}$ months (Continued)

$$
\begin{aligned}
& \text { tracted for } \\
& \text { infants un- } \\
& \text { der } 1 \\
& \text { month old } \\
& \text { who had } \\
& \text { been al- } \\
& \text { located to } \\
& \text { treatment }
\end{aligned}
$$

\begin{tabular}{|c|c|c|c|c|c|c|c|c|c|}
\hline Study ID & $\begin{array}{l}\text { Analyzed } \\
\text { as Rate/ } \\
\text { Risk ratio }\end{array}$ & $\begin{array}{l}\text { Data } \\
\text { source }\end{array}$ & Infants & $\begin{array}{l}\text { Vitamin A } \\
\text { group: } \\
\text { Deaths }\end{array}$ & $\begin{array}{l}\text { Vitamin A } \\
\text { group: } \\
\text { Child- } \\
\text { years of } \\
\text { follow-up }\end{array}$ & $\begin{array}{l}\text { Vitamin A } \\
\text { group: } \\
\mathbf{N}\end{array}$ & $\begin{array}{l}\text { Control } \\
\text { group: } \\
\text { Deaths }\end{array}$ & $\begin{array}{l}\text { Control } \\
\text { group: } \\
\text { Child- } \\
\text { years of } \\
\text { follow-up }\end{array}$ & $\begin{array}{l}\text { Control } \\
\text { group: } \\
\mathrm{N}\end{array}$ \\
\hline Benn 2008 & $\begin{array}{l}\text { Rate ratio/ } \\
\text { risk ratio }\end{array}$ & $\begin{array}{l}\text { Benn et al, } \\
\text { BMJ } \\
2008 ; 336 \\
(7658): \\
1416-20 .\end{array}$ & All infants & 88 & 1795 & 2106 & 86 & 1884 & 2169 \\
\hline Benn 2010 & $\begin{array}{l}\text { Rate ratio/ } \\
\text { risk ratio }\end{array}$ & $\begin{array}{l}\text { Benn et al, } \\
\text { BMJ } \\
2010 ; 340 \text { : } \\
\text { c1101. }\end{array}$ & All infants & 83 & 757 & 701 & 78 & 762 & 710 \\
\hline $\begin{array}{l}\text { Humphrey } \\
1996\end{array}$ & $\begin{array}{l}\text { Rate ratio/ } \\
\text { risk ratio }\end{array}$ & $\begin{array}{l}\text { Humphrey } \\
\text { et al, Jour- } \\
\text { nal of Pedi- } \\
\text { atrics } \\
1996 ; 128 \\
\text { (4):489- } \\
96 .\end{array}$ & $\begin{array}{l}\text { All } \\
\text { infants (in- } \\
\text { cludes } 6 \% \\
\text { preterms) }\end{array}$ & 7 & 969.6 & 925 & 19 & 957.1 & 914 \\
\hline $\begin{array}{l}\text { Klemm } \\
2008\end{array}$ & - & - & - & - & - & - & - & - & - \\
\hline $\begin{array}{l}\text { Malaba } \\
2005\end{array}$ & $\begin{array}{l}\text { Rate ratio/ } \\
\text { risk ratio }\end{array}$ & $\begin{array}{l}\text { Malaba } \\
\text { et al, The } \\
\text { American } \\
\text { Journal of }\end{array}$ & All infants & 88 & 4195 & 4079 & 82 & 4239 & 4127 \\
\hline
\end{tabular}

Klemm 2008 was a cluster randomised study. The study authors reported that observed design effect was $0.9 \%$.

West 1995 was a cluster randomised study. The study authors reported that the $95 \%$ confidence intervals of the effect estimates were inflated by $10 \%$ to account for the impact of the design on the study. We estimated that the $10 \%$ increase in the $95 \%$ CIs gave an ICC of 0.04 for the cohort of infants administered Vitamin A.

Table 2. Data type and source: all-cause infant mortality at 12 months 
Table 2. Data type and source: all-cause infant mortality at $\mathbf{1 2}$ months (Continued)
Clinical
Nutrition
2005;81
(2):454-
60. Data
aggre-
gated for
the four
treatment
groups:
Maternal
vitamin $\mathrm{A}$
and infant
vitamin A
+ maternal
placebo
and infant
vitamin
A versus
maternal
placebo
and infant
placebo +
maternal
vitamin $\mathrm{A}$
and infant
placebo

\begin{tabular}{|c|c|c|c|c|c|c|c|c|c|}
\hline $\begin{array}{l}\text { Rahmath- } \\
\text { ullah } \\
2003\end{array}$ & - & - & - & - & - & - & - & - & - \\
\hline West 1995 & - & - & - & - & - & - & - & - & - \\
\hline
\end{tabular}

\section{WHAT'S NEW}

Last assessed as up-to-date: 30 November 2010.

\begin{tabular}{l|l|l}
\hline Date & Event & Description \\
\hline 13 March 2012 & Amended & Minor typographical error corrected. \\
\hline
\end{tabular}




\section{H I S T O R Y}

Protocol first published: Issue 1, 2008

Review first published: Issue 10, 2011

\begin{tabular}{lll}
\hline Date & Event & Description \\
\hline 14 May 2008 & Amended & Reference correction \\
\hline 8 May 2008 & Amended & Converted to new review format. \\
\hline 12 October 2007 & New citation required and major changes & Substantive amendment \\
\hline
\end{tabular}

\section{CONTRIBUTIONSOFAUTHORS}

The review protocol was written by Batool A Haider (BAH) under the guidance of Zulfiqar A Bhutta (ZAB). Data extraction was done by $\mathrm{BAH}$ and $\mathrm{ZAB}$. BAH entered the data, created the comparisons, did data analysis and wrote the text of the review. ZAB provided supervision and contributed to the writing process of the review.

\section{DECLARATIONSOF INTEREST}

Zulfiqar A Bhutta is a principal investigator of an ongoing neonatal vitamin A supplementation trial in Pakistan.

\section{SOURCES OF SUPPORT}

\section{Internal sources}

- The Aga Khan University Hospital, Pakistan.

\section{External sources}

- World Health Organization, Switzerland.

A grant was provided by the WHO to fund the completion of this Cochrane Review.

\section{DIFFERENCES BETWEEN PROTOCOLANDREVIEW}

None 


\section{INDEX TERMS}

\section{Medical Subject Headings (MeSH)}

${ }^{*}$ Developing Countries; ${ }^{*}$ Infant Mortality; ${ }^{*}$ Morbidity; Randomized Controlled Trials as Topic; Vitamin A [ ${ }^{*}$ administration \& dosage]; Vitamin A Deficiency [prevention \& control]; Vitamins [*administration \& dosage]

\section{MeSH check words}

Humans; Infant, Newborn 